\title{
A Comprehensive Review of Graphene Nanocomposites: Research Status and Trends
}

\author{
Vivek Dhand, ${ }^{1}$ Kyong Yop Rhee, ${ }^{1}$ Hyun Ju Kim, ${ }^{2}$ and Dong Ho Jung ${ }^{2}$ \\ ${ }^{1}$ Department of Mechanical Engineering, College of Engineering, Kyung Hee University, Yongin 446-701, Republic of Korea \\ ${ }^{2}$ Maritime and Ocean Engineering Research Institute, Korea Institute of Ocean Science and Technology, \\ Daejeon 305-600, Republic of Korea \\ Correspondence should be addressed to Kyong Yop Rhee; rheeky@khu.ac.kr
}

Received 22 August 2013; Accepted 3 October 2013

Academic Editor: Chunsheng Shi

Copyright (C) 2013 Vivek Dhand et al. This is an open access article distributed under the Creative Commons Attribution License, which permits unrestricted use, distribution, and reproduction in any medium, provided the original work is properly cited.

\begin{abstract}
This paper provides a comprehensive review of the present trends in graphene research with an emphasis on graphene-based nanocomposites and their applications. Various synthesis routes have recently been devised for mass production of graphene to address the needs of the composite industry. This paper describes the worldwide scenario of research and patents being conducted in the field of graphene nanocomposites. It concludes with a discussion of the impact of graphene in composites and the future challenges to meeting industrial demands.
\end{abstract}

\section{Introduction to Graphene}

The single-layered atom-thick flatbed structure has revolutionized the nanotechnology platform since its discovery [1]. To date, several attempts have been made to synthesize graphene on a large scale to address the needs of various industries, particularly the composite industry, in which the use of graphene has dramatically transformed the global market for the production of state-of-the-art composite materials. The addition of graphene to a host matrix has achieved a number of enhanced properties with promising applications in many industries, such as aerospace, electronics, energy, structural and mechanical, environmental, medicine, and food and beverage. Since 2004, graphene has taken the nanotechnology platform by storm, with exponential growth in its applications. The remarkable properties of graphene make it a "magic bullet" for the composite world. Several papers on graphene and graphene-based nanocomposites have been published. According to Geim [2], graphene research has reached an unexpectedly great height and has emerged as a champion in the field of applied sciences. A simple search in Web of Science, Google Scholar, or Science-Direct yields several thousands of papers on graphene. Since 2000, there have been a total of 23,945 research papers published on various synthesis methods and on isolation of graphene on a large scale. The numbers are still growing exponentially. An analysis using the Web of Science tool reveals that the majority of graphene publications come from countries of Asia, followed by Europe, the Americas (countries between Canada and Argentina), Australia, and Africa. Our record count analysis based on subject-wise publications found that the majority of the publications were published in the area of physics, followed by chemistry, materials science, technology-based topics, engineering, electrochemistry, polymer science, and many more.

According to the latest report released by the $\mathrm{BBC}$, "Graphene: Technologies, Applications and Markets," the graphene business is projected to boom up to $\$ 67$ million by the year 2015 and $\$ 680$ by 2020, with a compound average annual growth rate (CAGR) of $58.7 \%$ in a span of 5 years. Based on a similar report on graphene, "The World Market for Graphene to 2017" by Future Markets Inc., by the year 2017 , the production volume of graphene is expected to grow to 573 tonnes from the initial growth of 28 tonnes in 2010 [3]. According to a recently published report by Sambasivudu and Yashwant [3], the annual growth of patents worldwide on graphene synthesis is becoming strong, and about 141 patents were published from 2001 to 2011. The report 
also extensively analyzed the global distribution of patents (including patent cooperation treaty (PCT) and European patent organization (EPO) classified on the basis of graphene synthesis). Analysis revealed that the United States has filed over 135 patents through 2011, followed by the Republic of Korea (82), China (44), Japan (37), and Europe (26). An interesting fact to note in this analysis is that the majority of the patents have been filed through the PCT and the United States Patent and Trademark Office (USPTO). This clearly indicates the importance and commercial exploitation of graphene technology on a global scale. A report by Frazier et al. (2009) [4] described in detail the patents filed for graphene and its synthesis, publications, and applications in various patent offices worldwide. It also provided detailed data of the number of papers published with graphene as a central word, from 2000 to 2008. Numerous methods have been devised to produce graphene on a laboratory scale. The primary one is the "scotch-tape method" [1] used for isolation of pure defect-free graphene for research purposes, followed by other synthesis processes like exfoliation methods $[1,5-$ 8], chemical vapor deposition (CVD) [5, 9-17], pyrolysis $[18,19]$, chemical synthesis [20-28], arc discharge [21, 2933], unzipping of CNT [34-45], solvothermal [9, 21, 46-48], epitaxial growth [5], molecular beam epitaxy [10, 49-60], and electrically-assisted synthesis [61-63].

The present review presents the current research trends in graphene synthesis and graphene-based nanocomposites. It describes related publications, patent overview, synthesis, and applications as well as the several previous reviews that have been published about graphene and its composites [21, 6466].

\section{Synthesis Approach of Graphene}

A long and coherent attempt of unsuccessful efforts to produce a single-layer graphene sheet has been made emphasizing the timely invention of a simple method presented by Novoselov's group in 2004 [1, 67, 68]. The group repeatedly peeled a graphite crystal using an adhesive tape until a specific limit and later transferred the thinned out graphite onto an extremely thin $(<300 \mathrm{~nm})$ appropriately colored, oxidized silicon wafer [67]. This remarkable discovery led to the onset of mass-scale production of graphene and its utilization in various polymeric, electronic industries. Over the last forty years, various unsuccessful attempts have been made to achieve large-scale production of pure, defect-free graphene sheets [67]. Recently, the method of epitaxial growth on metal carbide, the CVD method, has shown promise for production of graphene [10, 67, 69]. Various methods have been devised and categorized into "top-down" and "bottom-up" processes. The following sections describe synthesis routes for graphene.

2.1. Top Down. Top-down approaches commence with an existing form of the bulk material and process it to create the final product. This approach may be cost efficient, depending on the material used. In general, it is limited to a lab scale and has limited quality control [4]. In this approach, graphene or altered graphene sheets are produced by either separation, peeling, cleaving, or exfoliation of graphite or its derivatives (graphite oxide (GO) and graphite fluoride (GF)) [26]. Researchers have been successful in fabricating a few layers of free-standing graphene sheets on both microand nanoscales [4]. However, since this approach involves great investment and produces relatively low yields, the need remains for mass scaled-up processes to address the needs of industries economically. Various mechanical processes have been involved in producing high-quality, defect-free graphene: mechanical exfoliation of graphite, sonication, functionalization, electrochemical exfoliation, super acid dissolution of graphite, alkylation of graphene derivatives, chemical reduction of aqueous/organically treated graphene oxide (GO), thermal exfoliation, and chemical reduction of GO $[26,49]$. A detailed account of synthesis of graphene by the exfoliation method, functionalization, and reduction along with its utilization in the fabrication of nanocomposites has been extensively reviewed by Potts et al. (2011) [70], providing thorough insight into the procedures followed by various authors. Similarly, Daniel et al (2012) [71] reviewed and extensively outlined the synthesis of graphene from various sources using several similar approaches. Several other papers are available online that review the synthesis of graphene using the top-down approach [34] in detail.

2.2. Bottom Up. The bottom-up approach consists of standard techniques such as epitaxial growth using metallic substrates by means of CVD [10, 50-54, 72, 73] or organic synthesis $[23,72,74,75]$, which depend on the choice of precursor chemicals and thermal degradation and decomposition of the $\mathrm{SiC}[19,51,53,54,73,76]$. Several other processes, such as arc discharge [29, 30, 77], chemical conversion [23, 27, 77, 78], CO reduction [79], CNT unzipping [35, 38, 8082], and self-organization of surfactants [83-85] have also been tried for synthesis of graphene and its derivatives. Of all these processes, CVD and epitaxial growth, which produce bantam quantities of flawless graphene sheets with larger size [49], may in future be attractive for mass-scale graphene production, in contrast to mechanical cleaving. Using CVD and epitaxial methods, graphene sheets find their way into fundamental research with a multitude of applications ranging from electronics to polymeric nanocomposites [1]. Also, production of large quantities of graphene sheets is dependent on the chemical precursors used during synthesis. In particular, graphite oxide (GO), chemically reduced graphite (CRG), and thermally reduced graphite (TRG) are ideal candidates for polymer nanocomposite applications [1, 24, $26,86-90]$. In the bottom-up approach, as discussed earlier, the small molecule chemicals and catalysts are determining factors for the specific control of morphology, crystallinity, and structure of graphene [91]. There are several accounts of using hydrocarbons as the source of graphene production and using metal catalysts through the CVD process [9194]. Currently, an Ni (111) surface is considered the best template for deposition of graphene due to the small variance in its lattice heterogeneity [91]. The control and stability in the graphene scale are potentially high, which makes CVD the most appealing method for device assembly and fabrication [91]. Nevertheless, this method faces a major 
challenge in the control of edge structure and topology [91]. Epitaxial growth of graphene on a $\mathrm{SiC}$ substrate is another common technique, in which decomposition of $\mathrm{SiC}$ results in the formation of graphene layers. The silicon is desorbed off the surface leaving highly pure defect-free graphene sheets [51, 91, 95, 96]. This process has several advantages, such as (i) there is no transition or transportation of the resulting material from the metal substrate to the dielectrictype substrate; (ii) the resultant graphene film is free from impurities; and (iii) controlled initiation and growth of the product can be tailored through the correct choice of substrate [91]. Recently, self-assembly processes, such as layerby-layer assembly (LLB), have been extensively employed to fabricate nanocomposite thin films using graphene. The resulting composite structure is expected to have well-aligned components [97-99]. Though the bottom-up approach to graphene synthesis presents less defects compared to the top-down approach, the operation and procedures are much harder, making it difficult to realize mass production for practical applications, and it is an expensive affair [72, 91]. Still, the most commonly chosen route of graphene synthesis is a bottom-up strategy because it offers incredible possibilities to tailor the atomic size, composition, shape, stability, and edge structure in graphenes [72]. Researchers around the globe are making strong efforts to develop a reliable strategy to produce defect-free, high functional quality and large quantity graphene using synthetic and processing protocols compatible with standard fabrication procedures at low cost $[72,91]$.

\section{Worldwide Research on Graphene and Graphene Nanocomposites}

Since its discovery, graphene has revolutionized and completely redefined modern day technology with its remarkable properties. The research has exponentially grown by numerous universities, R\&D establishments, and many more private and governmental bodies around the world. Research on graphene can be found in every discipline, as of today. In the present section, looking into current prospects, we provide an overview of a number of published works, which illustrates the impetus in graphene research around the globe. The following sections briefly address the present scenario and the importance of graphene research. The several review articles published through 2010 highlight the quality and quantity of graphene research on the basis of publications with an aim towards patenting. Here, we attempt to update this trend and showcase the current growth of publications and patents.

3.1. Quantity of Publications in Graphene Since 2000. Using the Web of Science tool, a clear representation of the publication trend for graphene is shown, indicating the quantity of graphene research being carried out globally. Figure 1 shows the publication trend since the year 2000 (January) that the amount of research has grown exponentially from 106 articles in the year 2000 to 8,169 articles in the year 2012 (December).

A total of 23,945 articles were retrieved through this search using the syntax string <graphene $>$. Using the same

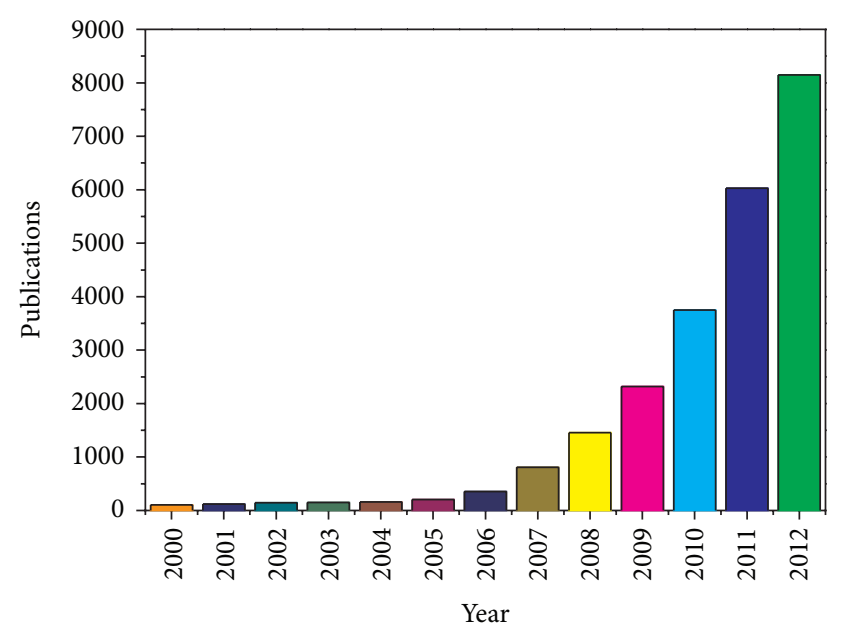

FIgURE 1: Publication trend in graphene chronology since 20002012.

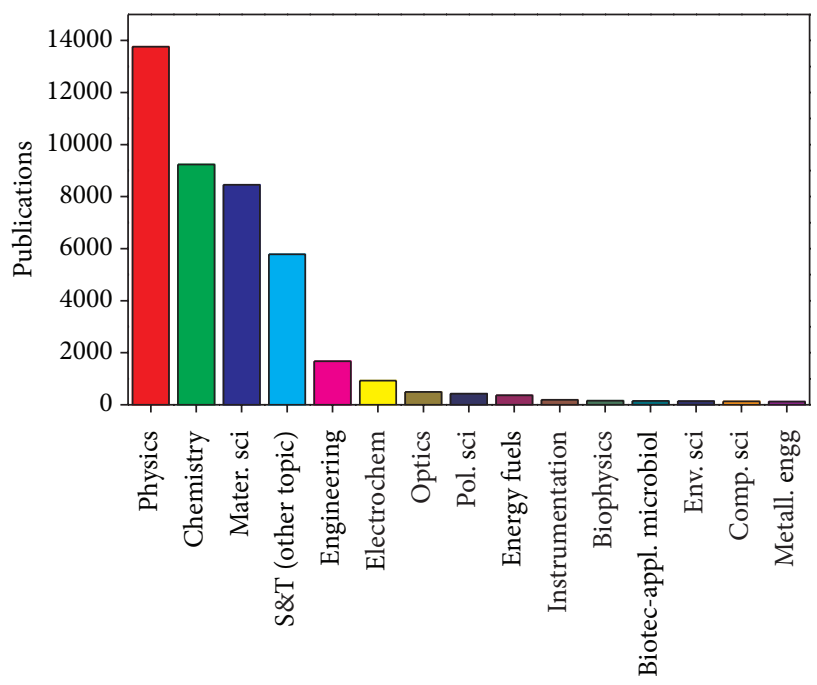

FIgURE 2: Top 15 research areas in which graphene is extensively used since 2000-2012.

tool (Web of Science), the results were further refined to assess the top research areas in which graphene is extensively used and the number of articles published since 2000.

As Figure 2 shows, physics (record count: 13,756) is the most often researched area, followed by chemistry $(9,231)$, materials science $(8,458)$, science and technology (5779), engineering (1677), electrochemistry (932), and so on. Research in the latter area is expected to grow at a rapid pace and in the future to compete with the forerunners. A countrywise refined search was conducted to assess the publication order in graphene research since 2000. Results (Figure 3) show that the United States tops the chart with the highest number of publications, 6,500, followed by China with 6,400, Japan with 1,979, South Korea with 1,648, and so on. This indicates the importance given to graphene research and the quantity of research around the globe. Considering the present scenario, it is estimated that by the year's end (2013), 


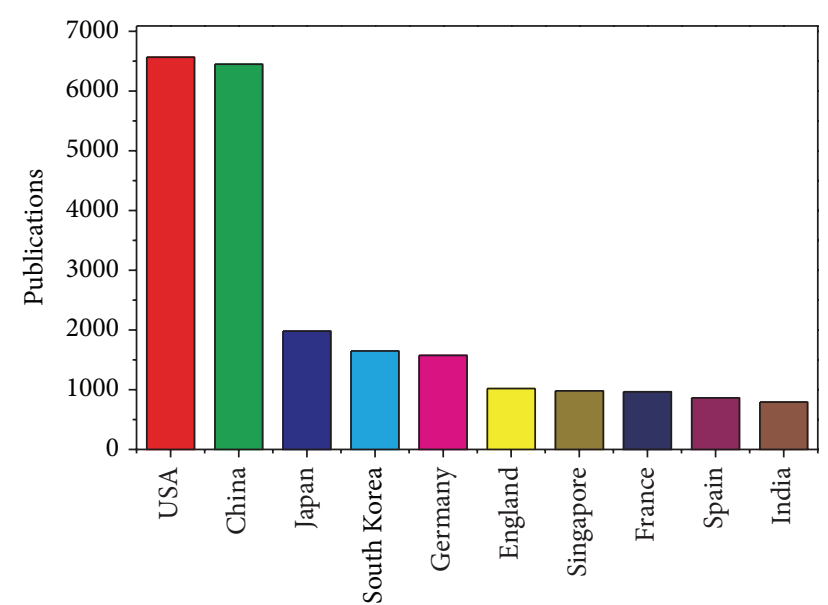

FIGURE 3: Country wise publications in graphene since 2000-2012.

competition will intensify among various countries for the highest position, quality, applications, patents, commercial products, and future markets of graphene.

3.2. Patents on Graphene Since 2000. Patents play a major role on the scientific and industrial platform. According to the data provided by Lv et al. (2011) [100], more than 50 countries have filed nearly 823 patents on graphene from January 2000 to December 2010, in 15 different disciplines. These data show that the top countries obtaining and applying for patents are the USA, followed by Asian nations. China, Japan, and South Korea contribute almost $25 \%$ of all the patents published in Asia. In the last ten years, Asian countries have recorded an explosive patent growth of almost $87 \%$ in the field of graphene [100]. Recently, Shapira et al. (2012) [101] used the Thompsons Reuters-Derwent Index to study graphene-based patents over the period 2000-2010. Their search found 4,787 graphene publications and 911 patents, with $97 \%$ of these patents being application oriented, indicating strong emergence of commercial applications. An increasing number of patents are regarded as indicators of breakthroughs in chronological performance [100].

In the present study, we used Thompson's Derwent Innovation Index to retrieve patent data for the strings <graphene> and <graphene nanocomposites> over the search time span from January 2000 to December 2012. The data retrieved on the total number of patents published on graphene during the years 2000-2012 was approximately 2,306 patents; thus, in a span of two years (2010-2012), compared to the results of Shapira et al. (2012), a strong jump occurred of nearly 1,395 patents. The results for the second search on graphene nanocomposites patents published during 2000-2012 retrieved only 80 records. Both searches showed that, during 2000-2007, there were no records of published patents on graphene and graphenebased nanocomposites. This can be attributed to the onset of trials to investigate the commercial importance of graphene in modern industry, with many researchers carrying out various trials to demonstrate high-end applications that

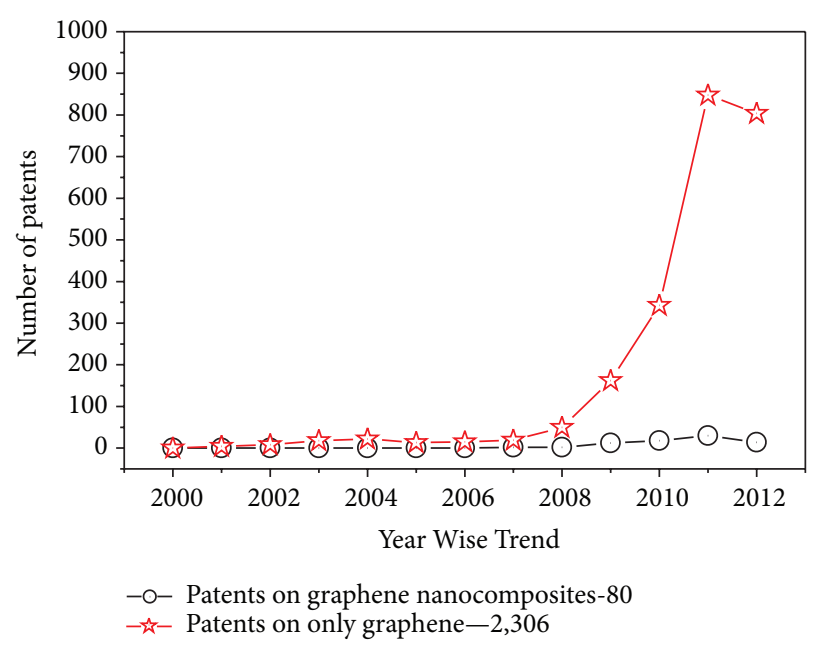

FIGURE 4: Patent trends of graphene and graphene nanocomposite since 2000-2012.

are likely to become available in the forthcoming years. We also conducted a cumulative search to see the trends and competition among the standalone graphene patents and graphene-based nanocomposites during January 2000December 2012.

From the graph (Figure 4), it is evident that the future of $\mathrm{R} \& \mathrm{D}$ for graphene-based nanocomposites is very bright with high prospects. Since the average annual number of patents and publications for graphene is very high and increasing dramatically, it appears that investigations of graphene's properties are likely to focus in the near future on nanocomposites as the primary area of application. The growing interest in graphene in various disciplines is depicted in Figures 5 and 6. Analysis of the various patents on graphene in the time frame January 2000-December 2012 reveals that the most examined subject area is chemistry (Figure 5). This shows that most of the graphene research continues to be based on the principles and properties of its chemistry. These results are consistent with those shown in Figure 2. Analysis (Figure 6) of the patents for the year 2012 found that most of the patents published in this year were related to the engineering field. This shift in subject area from chemistry to engineering indicates that more applicationbased patents were published. A refined analysis shows that most of the applications were based on mechanical and structural designs, consistent with the use of nanocomposites in engineering applications. These results are consistent with the findings described at the beginning of this section. It is remarkable that, in the year 2012, 789 patents on graphene and 14 patents on graphene nanocomposites were published. A recent estimate shows that the over years (2004-till date) the funding in grapheme-based composites has also increased several folds. It is estimated that the United States has spent more than $\$ 760$ million on graphene composite research. Also, more recently, a business week magazine reported that the European Union (EU) has invested around \$1.35 billion in graphene industry with an 18-month target to release its first grapheme-based product in the market. Also, parallel 


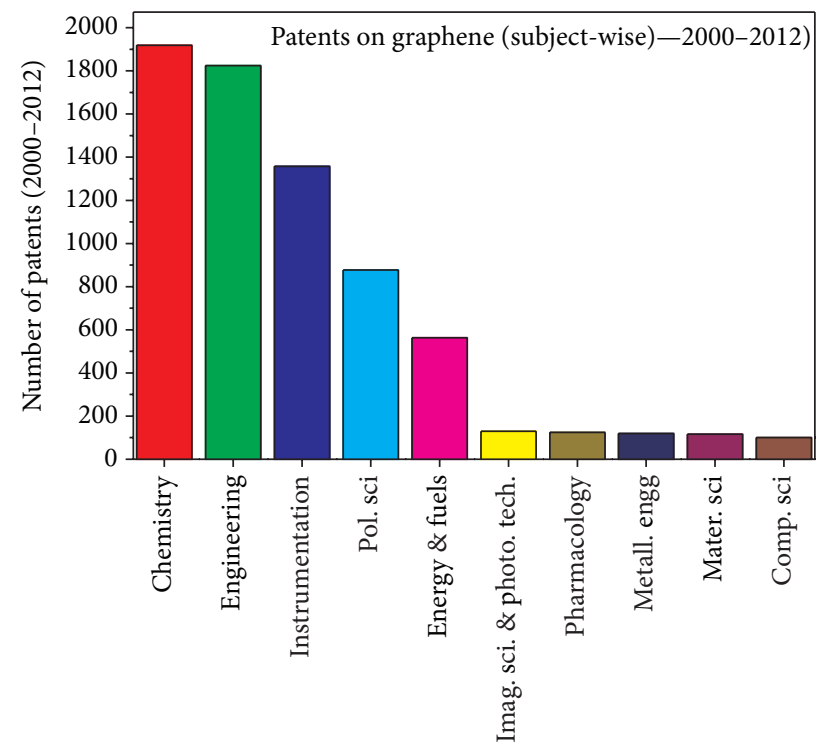

FIGURE 5: Subject-wise patent trend of graphene since 2000-2012.

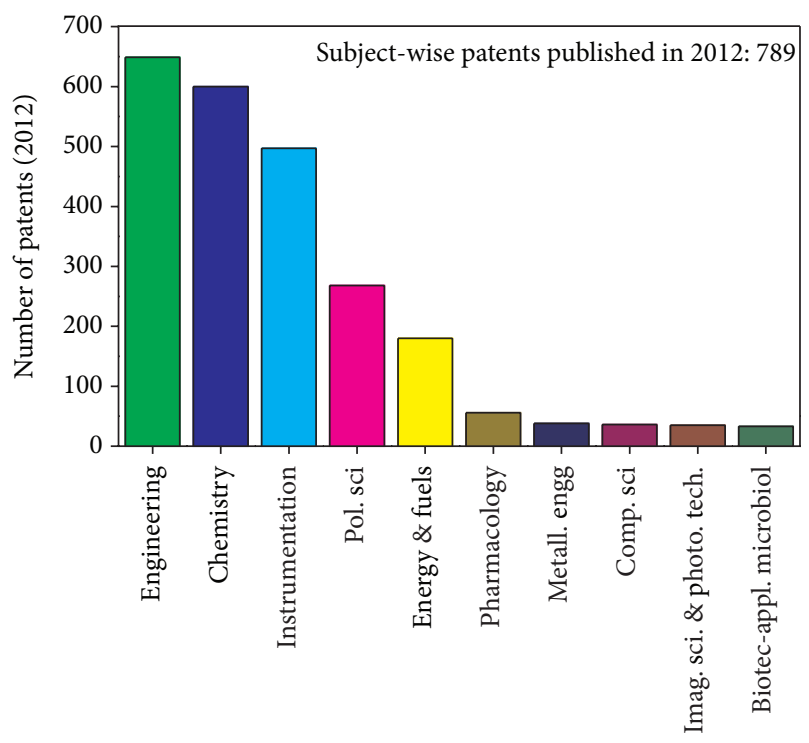

FIGURE 6: Subject-wise patent trend of graphene in 2012.

to this, research has shown increased citations in graphene nanocomposites over the years. Figure 7 shows the citation trend of graphene nanocomposite since 2000 till date with a total count of 22,500 .

The increasing trend of citation shows the tremendous output in graphene nanocomposite research which may in future completely revolutionize and conquer the global market.

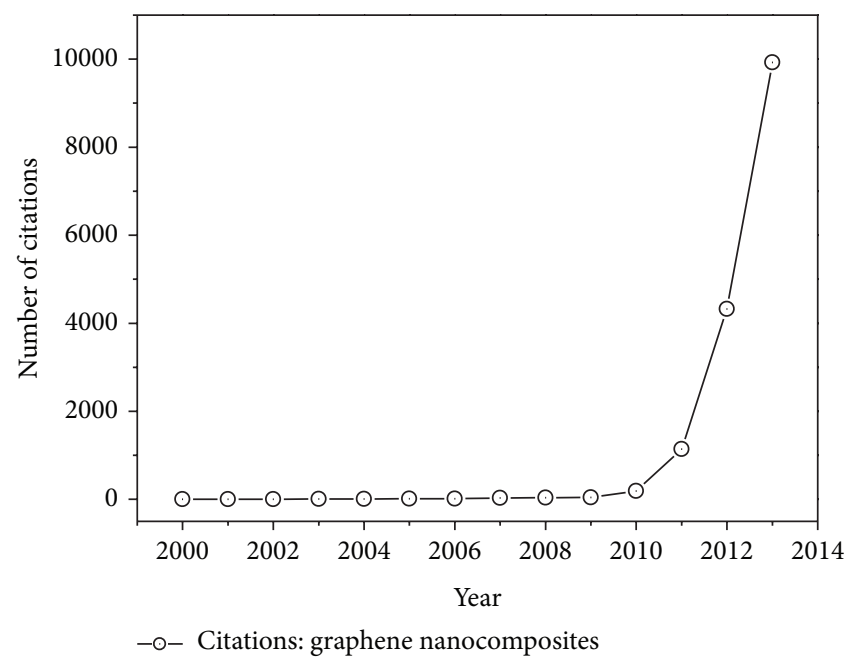

FIGURE 7: Citation trend of graphene nanocomposites since 20002013

\section{Graphene-Based Nanocomposites and Their Importance}

Because of graphene's exceptional thermal, mechanical, and electronic properties $[70,102,103]$, it stands out as the most promising candidate to be a major filling agent for composite applications [70]. Graphene nanocomposites at very low loading show substantial enhancements in their multifunctional aspects, compared to conventional composites and their materials. This not only makes the material lighter with simple processing, but also makes it stronger for various multifunctional applications $[70,104,105]$. As stated in previous sections, the remarkable properties of graphene are able to improve the physicochemical qualities of the host matrix upon distribution. This helps in strengthening and increasing the interfacial bonds between the layers of graphene and the host matrix. It is this bonding that dictates the emergence of the cumulative properties of graphene in reinforced nanocomposites [106]. Kuilla et al. (2010), in their extensive review article on graphene-based polymer nanocomposites, have systematically explained the importance and use of graphene in various host materials. They also carried out a remarkable comparison of various nanofillers and listed their important applications in detail [106]. In the world of composites, theoretical analysis plays a crucial role in understanding their mechanisms, molecular interactions, and physical properties and their potential applications. A number of simulation tools provide cumulative or specific results for composite analysis. With the aid of these computational tools, a broad understanding and guide to successful research can be systematically achieved. Such theoretical investigations help the investigators to precisely optimize their case study to perfect the composite product [107]. In recent years, there has been some significant research papers on graphene-based composites with a polymer matrix. Jang and Zhamu (2008) reviewed the processing of graphene nanoplatelets (GNPs) for fabrication of composite materials [108]. Mack et al. (2005) prepared nanocomposites of 
polyacrylonitrile (PAN) nanofibers strengthened by GNP, which they demonstrated to have improved mechanical qualities [109]. Research by Hansma et al. (2007) showed successful fabrication of graphene-based nanocomposites. They successfully optimized the amount and combination of adhesives and high-strength nanostructures (graphene) needed to yield a strong, low-density, lightweight, and damage resistant composite material [110]. Ramanathan et al. (2008) reported an unprecedented shift in the glass transition temperature $\left(T_{g}\right)$ of a polymer nanocomposite with functionalized graphene sheets. They observed that, by the addition of functionalized graphene sheets (1 wt\%) to the polyacrylonitrile (PAN), the $T_{g}$ of the composite material increased by $40^{\circ} \mathrm{C}$, whereas, when only $0.5 \mathrm{wt} \%$ was added to polymethyl methacrylate (PMMA), they observed a $30^{\circ} \mathrm{C}$ rise in $T_{g}$ [111]. Also, they observed that by addition of $1 \mathrm{wt} \%$ graphene to PMMA, an $80 \%$ increase resulted in the elastic modulus and a $20 \%$ increase resulted in the ultimate tensile strength. Their comparative research concluded that monolayered functionalized graphene serves as the best nanofiller among all examined nanofillers [111]. Das et al. (2009) employed the nanoindentation technique to the graphene-reinforced nanocomposite fabricated by using polyvinyl alcohol (PVA) and PMMM. The results showed significant improvement in crystallinity, elastic modulus, and hardness through the addition of only $0.06 \mathrm{wt} \%$ of graphene. The authors suggested that the enhancement was due to close mechanical interaction between the host (polymer) matrix and the layers of graphene. This interaction successively provides and dictates a better load transfer within the host matrix and the nanofiller [112]. Yu et al. (2007) identified that epoxy-based few-layer graphene nanocomposites show fascinating properties for the electronics industry, ideal for development of thermal-interface-based materials [113]. Zhang et al. (2009) and Liu et al. (2009) successfully synthesized graphene-fullerene-based hybrid nanocomposites [114, 115]. Booth et al. (2008) demonstrated the successful synthesis of robust $100 \mu \mathrm{m}$ thick macroscopic graphene membranes that can bear heavy loads [116]. According to Luechinger et al. (2008), the introduction of metal nanoparticles in the host matrix along with graphene has attracted a lot of researchers due to the advantage it provides by facilitating an improved interparticle contact (i.e., contact between the metal particle and the host matrix) [117]. Watcharotone et al. (2007) fabricated a transparent, electrical conductor by employing a simple sol-gel, spin-coating, chemical reduction, and thermal-curing route. The group used graphene oxide (GO) sheets mixed in the silica solution to obtain metal-encapsulated graphene nanocomposites [118]. In 2008, Chen et al. [119] fabricated graphene conducting paper that was electrically conducting, mechanically strong, and biocompatible. They uniformly dispersed graphene sheets in a solution using vacuum filtration followed by moderate thermal annealing. Recently, Cheng et al. (2013) synthesized carbon-coated SnO-graphene sheet composites in a green approach via a single-pot hydrothermal route. The composite was fabricated as an anode material for an Li-ion battery, and it exhibited high storage capacity and improved cyclic performance [120]. Similarly, Perera et al. (2013) synthesized $\mathrm{V}_{2} \mathrm{O}_{5}$ nanowire-graphene nanocomposite as an electrode material. The composite electrode exhibited an equilibrated electric double layer (EDL), energy density of $38.8 \mathrm{Wh} \mathrm{kg}^{-1}$, and pseudocapacitance at a power density of $455 \mathrm{~W} \mathrm{~kg}^{-1}$, and, also, the composite material showed a high specific capacitance of $80 \mathrm{Fg}^{-1}$. These results clearly indicate that the composite electrode was capable of effective storage and deliverance of charges toward high energy applications [121]. Lee et al. (2013) used cryomilling to synthesize fine particles of graphene and chitosan. The mixture was sonicated and layered to form a composite. The graphene particles conferred a cumulative effect in improving the mechanical attributes of the composite and also decreased the agglomeration quotient of graphene during mixing [122]. Guo et al. (2011) prepared a water-dispersed graphene-tryptophanPVA nanocomposite for improving tensile strength, modulus, and thermal stability. There was a $23 \%$ increase in tensile strength when only a small loading of graphene $(0.2 \mathrm{wt} \%)$ was introduced in the PVA matrix [123]. Ansari et al. (2013) studied the DC electrical conductivity retention of their indigenously prepared graphene-Pani-MWCNT nanocomposite in air and also assessed the cyclic aging. They found that Pani-graphene showed higher electrical conductivity and good stability for the DC electrical conductivity retention under isothermal conditions [124]. Jeon et al. (2012) prepared an exfoliated-grapheme- (EG-) cellulose acetate nanocomposite using the melt compounding method. They found that exfoliated graphene (EG) was uniformly dispersed in the host matrix with lower loadings. They also found that the composite had high thermal stability and improved conductivity and modulus [125]. The great number of application- and property-oriented possibilities suggests that future research and prospects for graphenebased nanocomposites are likely to expand tremendously in every discipline, with many surprises and products in store.

\section{Applications of Graphene-Based Nanocomposites}

Graphene has a great number of applications encompassing engineering, electronics, medicine, energy, industrial, household design, and many more $[126,127]$. A previous review search yielded several review papers that examined fieldoriented and specific applications of graphene. Majority of the papers dealt with electronic/sensor-oriented applications, to generalize the broad applications of graphene and graphenebased nanocomposite into their respective disciplines. Shen et al. (2012) extensively reviewed the biomedical applications of graphene including drug delivery, gene delivery, cancer therapy, biosensing and bioimaging, GO-based antibacterial materials, and scaffolds for tissue/cell culturing [128]. Similarly, Huang et al. (2011) and Choi et al. (2010) explained various phenomena associated with graphene and graphenebased materials and their applications in the field of memory devices for electronics, ranging from electrochemical sensors to instrumentation $[127,129]$. 
5.1. Biological Applications of Graphene and Graphene-Based Nanocomposites. Graphene in various derivatives and in its precursor form has also shown potential applications in biological/medical fields, especially related to toxicity. Hu et al. (2010) demonstrated the antibacterial activity of two types of water dispersible graphene against $E$. coli with minimum cytotoxic effects on the human participants. The group concluded that GO paper can one day be effectively used in various environmental and biological applications [130]. Liao et al. (2011) demonstrated the cytotoxicity effect of graphene and graphene oxide (GO) materials under controlled physicochemical parameters. The results showed that GO was more severely hemolytic than graphene and showed high activity under extremely small size. They observed that, when chitosan was coated on GO, the hemolytic activity disappeared completely, showing the biocompatibility of the composite for erythrocytes. They concluded that the biological or toxicological responses of the material were dependent on the particle size, quality, and state, the surface charge, and the oxygen threshold [131]. Similarly, Liu et al. (2011) compared four different types of graphene materials (graphite (Gt), graphite oxide (GtO), GO, and reduced graphene oxide (rGO)) against E. coli, to study the toxicity effects. The membrane and oxidative stress signals were used to measure the intensity of toxicity. Their results showed that GO was the most severely toxic, followed in descending order by rGO, Gt, and GtO [132]. Santos et al. [133, 134] reported the design, fabrication, and antimicrobial application of a graphene-poly- $\mathrm{N}$ vinyl carbazole (PVK) nanocomposite, resulting in more than $80 \%$ microbial inhibition and toxicity toward a broad array of bacteria. Carpio et al. (2012) studied the toxicity effects of PVK-GO nanocomposite onplanktonic microbial cells, E. coli, C. metallidurans B. subtilis and R. opacus, biofilms, and mammalian fibroblast cells (NIH 3T3). Their results showed that PVK-GO presented a stronger antimicrobial effect than pristine GO. They also found that the PVK-GO was significantly neutral toward the fibroblast cells, indicating a huge potential of the composite material in biomedical and industrial applications [135]. Peng et al. (2012) studied an $\mathrm{Mn}$-ferrite $\left(\mathrm{MnFe}_{2} \mathrm{O}_{4}\right)$-decorated $\mathrm{GO}$ nanocomposite for biomedical applications. They observed that the magnetic property of the ferrites can be effectively used as an ideal hyperthermia and $T_{2}$ contrast MRI agent. The nanocomposite when PEGylated showed excellent biocompatibility [136]. Recently, Liu et al. (2013) synthesized a hydroxyapatiteGO nanocomposite as biocompatible prosthetic. They found that the (300) and (002) plane hydroxyapatite nanorods in the graphene matrix played a crucial role in maintaining the composite's mechanical properties. Given its superior mechanical property, the authors suggested the nanocomposite's potential in composite and biomedical industries [136]. Many other applications of graphene nanocomposites in the field of electronics and other disciplines have been reported. Generalized applications of various kinds of graphene-based nanocomposites have been described in the literature. These include sensors [137-141], Li-Ion batteries [120, 121, 142147], fuel cells [148-152], solar cells [153-158], field emission $[159,160]$, super capacitors [161-172], thermal transport and stability [173-175], packaging industry [176-178], corrosion
$[179,180]$, fire packaging and resistance [181], and many more. We expect that, very soon, all these applications will be available from manufacturers to end users at common commercial stores.

\subsection{Ceramic Reinforced Graphene Nanocomposites and Their} Application. The recent use of ceramics in grapheme-based nanocomposite has sparked a global interest. The introduction of ceramic materials in few-layered graphene results in the formation of a composite yielding exceptional electrochemical performance with high charge carrier properties. The exploitation of such properties is a boon to the energy industry [182]. Several ceramic-graphene composites like SiC-Graphene [183], $\mathrm{Si}_{3} \mathrm{~N}_{4}$-graphene [184, 185], $\mathrm{Al}_{2} \mathrm{O}_{3}$ graphene [186], $\mathrm{ZrB}_{2}$-graphene [187], $\mathrm{ZrO}-\mathrm{Al}_{2} \mathrm{O}_{3}$-graphene [188], BN-Graphene [189], and many more are known to enhance not only electrical properties but also thermal conductivity, refractory, mechanical, antifriction, anticorrosive and biocompatibility properties for diverse applications. Use of ceramics within graphene matrix can help overcome the brittle nature, lower fracture toughness, and limited thermal shock resistance in the composite industry. The use of $\mathrm{ZrB}_{2}$-graphene [187] is presently known to be used in aerospace industry as a high temperature barrier for space vehicle during the reentry event. These materials (ultrahigh temperature ceramic composites) are consistently used as the primal infrastructure for the nose caps in space shuttles and military ballistic equipment. Several other ultrahigh temperature ceramic composites have shown promising results. A few ultrahigh temperature ceramic composites are known to exist, for example, carbides of $\mathrm{Ta}, \mathrm{Zr}, \mathrm{Hf}, \mathrm{Nb}$, and borides of $\mathrm{Hf}, \mathrm{Zr}$, and $\mathrm{Ti}$, respectively [187]. Recently, Lahiri et al. (2013) have shown that with the introduction of short CNTs as reinforcement within the $\mathrm{TaC}$ ceramics, one can induce the formation of mulitlayers of graphene within the host matrix during the spark plasma sintering. This procedure helps in offering high resistance to pullout which results in higher strength material with delayed fracture [190]. Similarly, Pejaković et al. (2010) reported the synthesis of carbon rich-hafnia thin films using PLD technique. The NMR results showed that the sample contained graphene aromatically bonded carbon atoms presumably in graphene phase [191]. TiN-graphene composites, on other hand, have shown promising results as a selective permeable membrane for hydrogen. The composite material according to Kim and Hong (2012) was prepared by hot press process. The disc obtained was used to study the hydrogen gas permeability between 0.1 and $0.3 \mathrm{MPa}$ and at 473,573 and $673 \mathrm{~K}$, respectively, using a Knudsen diffusion model. The results obtained showed that the hydrogen permeability of TiNgraphene composites was better than the $\mathrm{Pd}-\mathrm{Ag}$ amorphous membrane at $1.67,2.09$, and $2.83 \times 10^{-7} \mathrm{~mol} / \mathrm{msPa}^{1 / 2}$ at $673 \mathrm{~K}$ under $0.3 \mathrm{MPa}$, respectively [192]. Almost similar results (2.62 $\times 10^{-7} \mathrm{~mol} / \mathrm{ms} \mathrm{Pa}^{1 / 2}$ at $673 \mathrm{~K}$ under $0.3 \mathrm{MPa}$ ) of hydrogen permeation were obtained recently by Lee et al. (2013) with the use of $\mathrm{Al}_{2} \mathrm{O}_{3} / \mathrm{CeO}_{2} /$ graphene (ACG) composite membranes prepared by hot-press method. By exploiting the pore size distribution, surface area, and elasticity, one can 
use such kinds of membranes for high purity separation and filtration of chemicals, biomolecules, petroleum products, and many more [193].

\section{Conclusions and Outlook}

Graphene- and polymers-based nanocomposites show promising growth in technology and applications [70]. However, a few key challenges must be addressed and resolved to realize the potential of graphene-based nanocomposites regarding synthesis methods, costs, and applications. For instance, if we consider the physical synthesis methods like sonication, exfoliation, and cleaving of GO, the resultant product (graphene) can have a reduced aspect ratio, which can drastically degenerate the reinforcement, bonding interactions, and thermal and electrical properties $[86,194]$ of both the graphene and the nanocomposites [70]. From the present review, it is clearly evident that both graphene and its derivatives have demonstrated their potential as promising candidates as reinforcements for highperformance nanocomposites [44]. Various reports have discussed the effects of the lower loadings of graphene and its derivatives, which result in high levels of strength and stiffness and superior mechanical properties [44]. Many reports have also discussed the good dispersion quality of graphene and its derivatives in different host matrices. As stated earlier, certain challenges remain to be resolved in obtaining large-scale, defect-free exfoliation of graphene with high quality and good properties. Since graphene tops the charts with its exceptional properties, the graphene-based product showcases itself in various day-to-day applications. Due to the quality and quantity of work, graphene has attracted worldwide attention in the mere five-year span since its emergence. The intensity and number of publications and patents arising from various countries and related subject areas have triggered a chain reaction in the field of electronics and other applications. It is expected that, by the year 2020, the graphene market will rise by a CAGR of $60 \%$. This remarkable growth in the coming five years predicts an exponential boom in graphene research and development worldwide. In fact, polymer-based graphene nanocomposites have already paved their way in global markets and are expected to rise even more in the future [195]. Various attempts are being made to further improve and enhance the properties of nanocomposites by altering the chemical structure of graphene and its derivatives through functionalization and encapsulation techniques at the production level [196]. In the recent applications of graphene-based nanocomposites, some researchers have used graphene as the only nanofiller, which has shown improved dispersions and properties over other nanofillers. Recently, Yadav et al. (2013) introduced graphene oxide as a nanofiller for synthesis of a biodegradable polymer nanocomposite made of carboxy methyl cellulose (CMC). The results showed strong adherence of $\mathrm{GO}$ and $\mathrm{CMC}$ via hydrogen bonding. This interaction resulted in a commensurate improvement of mechanical properties with excellent dispersion of GO within the CMC matrix. The composite was reported to be more thermally stable and mechanically robust [197].
According to Segal (2009) [198], there has been a significant output in producing mass-scale production of graphene oxide (GO), and, similarly, platelets of graphene (GNP) have also gathered interest as nanofillers; they have also been in mass production since the onset of graphenebased nanocomposite [70]. Graphite is relatively affordable and is abundantly available around the globe [198], and it is the only chief source (precursor) for the production of graphene and graphene-derived nanofillers. This is due to the affinity of GO and its derivatives toward the host matrix, resulting in strong interaction and bonding. This has made graphene a promising nanofiller candidate, just next to carbon nanotubes, which it is likely to replace in the future. The present day composite industry is utilizing more and more of these GO nanofillers in their products on large and commercial scales. Use of ceramic reinforced graphene composites can be highly advantageous in the fields of chemical, biological, and petroleum products since ceramics-graphene composites are highly stable, robust, recyclable and chemically inert. Their use as thermal barriers and refractory applications paves their way into space science helping the engineers/scientist to understand the thermodynamics and stability of material during reentry events of space vehicles and military equipment or ballistics. Since most of the ceramic materials are biocompatible they can find their use in modern surgical equipment and as prosthetics in biomedical engineering area. Due to the high diversity, properties, and advantages of graphene, a multitude of nanocomposite-based applications have been envisioned to be practical. These multifunctional graphene composites coupled with affordable cost will soon be seen in the global market.

\section{Acknowledgment}

This work was financially supported by the National R\&D project of "Development of Energy Utilization Technology of Deep Sea Water Resource" supported by the Ministry of Oceans and Fisheries of the Republic of Korea.

\section{References}

[1] K. S. Novoselov, A. K. Geim, S. V. Morozov et al., "Electric field in atomically thin carbon films," Science, vol. 306, no. 5696, pp. 666-669, 2004.

[2] A. K. Geim, “Graphene: status and prospects," Science, vol. 324, no. 5934, pp. 1530-1534, 2009.

[3] K. Sambasivudu and M. Yashwant, "Challenges and opportunities for the mass production of high quality graphene: an analysis of worldwide patents," Nanotech Insights, 2012.

[4] R. M. Frazier, D. T. Daly, R. P. Swatloski, K. W. Hathcock, and C. R. South, "Recent progress in graphene-related nanotechnologies," Recent Patents on Nanotechnology, vol. 3, no. 3, pp. 164176, 2009.

[5] S. Park and R. S. Ruoff, "Chemical methods for the production of graphenes," Nature Nanotechnology, vol. 4, no. 4, pp. 217-224, 2009. 
[6] X. Lu, M. Yu, H. Huang, and R. S. Ruoff, "Tailoring graphite with the goal of achieving single sheets," Nanotechnology, vol. 10, no. 3, pp. 269-272, 1999.

[7] D. Pan, S. Wang, B. Zhao et al., "Li storage properties of disordered graphene nanosheets," Chemistry of Materials, vol. 21, no. 14, pp. 3136-3142, 2009.

[8] H. L. Guo, X. F. Wang, Q. Y. Qian, F. Wang, and X. Xia, "A green approach to the synthesis of graphene nanosheets," ACS Nano, vol. 3, no. 9, pp. 2653-2659, 2009.

[9] K. S. Kim, Y. Zhao, H. Jang et al., "Large-scale pattern growth of graphene films for stretchable transparent electrodes," Nature, vol. 457, no. 7230, pp. 706-710, 2009.

[10] P. W. Sutter, J. Flege, and E. A. Sutter, "Epitaxial graphene on ruthenium," Nature Materials, vol. 7, no. 5, pp. 406-411, 2008.

[11] X. Li, W. Cai, J. An et al., "Large-area synthesis of high-quality and uniform graphene films on copper foils," Science, vol. 324, no. 5932, pp. 1312-1314, 2009.

[12] M. Eizenberg and J. M. Blakely, "Carbon monolayer phase condensation on Ni(111)," Surface Science, vol. 82, no. 1, pp. 228 236, 1979.

[13] A. Reina, X. Jia, J. Ho et al., "Large area, few-layer graphene films on arbitrary substrates by chemical vapor deposition," Nano Letters, vol. 9, no. 1, pp. 30-35, 2009.

[14] A. Dato, V. Radmilovic, Z. Lee, J. Phillips, and M. Frenklach, "Substrate-free gas-phase synthesis of graphene sheets," Nano Letters, vol. 8, no. 7, pp. 2012-2016, 2008.

[15] T. Yamada, J. Kim, M. Ishihara, and M. Hasegawa, "Lowtemperature graphene synthesis using microwave plasma CVD," Journal of Physics D, vol. 46, no. 6, Article ID 063001, 2013.

[16] T. Aizawa, R. Souda, S. Otani, Y. Ishizawa, and C. Oshima, "Anomalous bond of monolayer graphite on transition-metal carbide surfaces," Physical Review Letters, vol. 64, no. 7, pp. 768771, 1990 .

[17] X. Li, Y. Zhu, W. Cai et al., "Transfer of large-area graphene films for high-performance transparent conductive electrodes," Nano Letters, vol. 9, no. 12, pp. 4359-4363, 2009.

[18] D. J. Campos, H. J. M. Romo, X. Jia et al., "Bulk production of a new form of sp2 carbon: crystalline graphene nanoribbons," Nano Letters, vol. 8, no. 9, pp. 2773-2778, 2008.

[19] T. Lu, Y. Zhang, H. Li, L. Pan, Y. Li, and Z. Sun, "Electrochemical behaviors of graphene- $\mathrm{ZnO}$ and graphene- $\mathrm{SnO}_{2}$ composite films for supercapacitors," Electrochimica Acta, vol. 55, no. 13, pp. 4170-4173, 2010.

[20] V. C. Tung, M. J. Allen, Y. Yang, and R. B. Kaner, "Highthroughput solution processing of large-scale graphene," Nature Nanotechnology, vol. 4, no. 1, pp. 25-29, 2009.

[21] C. N. R. Rao, A. K. Sood, K. S. Subrahmanyam, and A. Govindaraj, "Graphene: the new two-dimensional nanomaterial," Angewandte Chemie, vol. 48, no. 42, pp. 7752-7777, 2009.

[22] W. Guoxiu, Y. Juan, P. Jinsoo et al., "Facile synthesis and characterization of graphene nanosheets," Journal of Physical Chemistry C, vol. 112, no. 22, pp. 8192-8195, 2008.

[23] X. Yang, X. Dou, A. Rouhanipour, L. Zhi, H. J. Räder, and K. Müllen, "Two-dimensional graphene nanoribbons," Journal of the American Chemical Society, vol. 130, no. 13, pp. 4216-4217, 2008.

[24] S. Stankovich, D. A. Dikin, R. D. Piner et al., "Synthesis of graphene-based nanosheets via chemical reduction of exfoliated graphite oxide," Carbon, vol. 45, no. 7, pp. 1558-1565, 2007.
[25] Y. Liang, D. Wu, X. Feng, and K. Müllen, "Dispersion of graphene sheets in organic solvent supported by ionic interactions," Advanced Materials, vol. 21, no. 17, pp. 1679-1683, 2009.

[26] K. A. Worsley, P. Ramesh, S. K. Mandal, S. Niyogi, M. E. Itkis, and R. C. Haddon, "Soluble graphene derived from graphite fluoride," Chemical Physics Letters, vol. 445, no. 1-3, pp. 51-56, 2007.

[27] Y. Carissan and W. Klopper, "Growing graphene sheets from reactions with methyl radicals: a quantum chemical study," ChemPhysChem, vol. 7, no. 8, pp. 1770-1778, 2006.

[28] L. Zhi and K. Müllen, "A bottom-up approach from molecular nanographenes to unconventional carbon materials," Journal of Materials Chemistry, vol. 18, no. 13, pp. 1472-1484, 2008.

[29] N. Li, Z. Wang, K. Zhao, Z. Shi, Z. Gu, and S. Xu, "Large scale synthesis of $\mathrm{N}$-doped multi-layered graphene sheets by simple arc-discharge method," Carbon, vol. 48, no. 1, pp. 255-259, 2010.

[30] S. Karmakar, N. V. Kulkarni, A. B. Nawale et al., "A novel approach towards selective bulk synthesis of few-layer graphenes in an electric arc," Journal of Physics D, vol. 42, no. 11, pp. 115201-115214, 2009.

[31] K. S. Subrahmanyam, L. S. Panchakarla, A. Govindaraj, and C. N. R. Rao, "Simple method of preparing graphene flakes by an arc-discharge method," Journal of Physical Chemistry C, vol. 113, no. 11, pp. 4257-4259, 2009.

[32] Z. S. Wu, W. Ren, L. Gao et al., "Synthesis of graphene sheets with high electrical conductivity and good thermal stability by hydrogen arc discharge exfoliation," ACS Nano, vol. 3, no. 2, pp. 411-417, 2009.

[33] O. Volotskova, I. Levchenko, A. Shashurin, Y. Raitses, K. Ostrikov, and M. Keidar, "Single-step synthesis and magnetic separation of graphene and carbon nanotubes in arc discharge plasmas," Nanoscale, vol. 2, no. 10, pp. 2281-2285, 2010.

[34] V. Singh, D. Joung, L. Zhai, S. Das, S. I. Khondaker, and S. Seal, "Graphene based materials: past, present and future," Progress in Materials Science, vol. 56, no. 8, pp. 1178-1271, 2011.

[35] L. Jiao, L. Zhang, X. Wang, G. Diankov, and H. Dai, "Narrow graphene nanoribbons from carbon nanotubes," Nature, vol. 458, no. 7240, pp. 877-880, 2009.

[36] C. Zhu, S. Guo, Y. Fang, and S. Dong, "Reducing sugar: new functional molecules for the green synthesis of graphene nanosheets," ACS Nano, vol. 4, no. 4, pp. 2429-2437, 2010.

[37] T. Shimizu, J. Haruyama, D. C. Marcano et al., "Large intrinsic energy bandgaps in annealed nanotube-derived graphene nanoribbons," Nature Nanotechnology, vol. 6, no. 1, pp. 45-50, 2011.

[38] D. V. Kosynkin, A. L. Higginbotham, A. Sinitskii et al., "Longitudinal unzipping of carbon nanotubes to form graphene nanoribbons," Nature, vol. 458, no. 7240, pp. 872-876, 2009.

[39] A. Sinitskii, A. Dimiev, D. V. Kosynkin, and J. M. Tour, "Graphene nanoribbon devices produced by oxidative unzipping of carbon nanotubes," ACS Nano, vol. 4, no. 9, pp. 5405$5413,2010$.

[40] A. Sinitskii, A. Dimiev, D. A. Corley, A. A. Fursina, D. V. Kosynkin, and J. M. Tour, "Kinetics of diazonium functionalization of chemically converted graphene nanoribbons," ACS Nano, vol. 4, no. 4, pp. 1949-1954, 2010.

[41] A. L. Elias, A. R. Botello-Méndez, D. Meneses-Rodríguez et al., "Longitudinal cutting of pure and doped carbon nanotubes to form graphitic nanoribbons using metal clusters as nanoscalpels," Nano Letters, vol. 10, no. 2, pp. 366-372, 2010. 
[42] L. Jiao, X. Wang, G. Diankov, H. Wang, and H. Dai, "Facile synthesis of high-quality graphene nanoribbons," Nature Nanotechnology, vol. 5, no. 5, pp. 321-325, 2010.

[43] L. Xie, L. Jiao, and H. Dai, "Selective etching of graphene edges by hydrogen plasma," Journal of the American Chemical Society, vol. 132, no. 42, pp. 14751-14753, 2010.

[44] R. J. Young, I. A. Kinloch, L. Gong, and K. S. Novoselov, “The mechanics of graphene nanocomposites: a review," Composites Science and Technology, vol. 72, no. 12, pp. 1459-1476, 2012.

[45] D. Wei, L. Xie, K. K. Lee et al., "Controllable unzipping for intramolecular junctions of graphene nanoribbons and singlewalled carbon nanotubes," Nature Communications, vol. 4, p. 1374, 2013.

[46] M. Choucair, P. Thordarson, and J. A. Stride, "Gram-scale production of graphene based on solvothermal synthesis and sonication," Nature Nanotechnology, vol. 4, no. 1, pp. 30-33, 2009.

[47] A. V. Murugan, T. Muraliganth, and A. Manthiram, "Rapid, facile microwave-solvothermal synthesis of graphene nanosheets and their polyaniline nanocomposites for energy strorage," Chemistry of Materials, vol. 21, no. 21, pp. 5004-5006, 2009.

[48] P. Wang, T. Jiang, C. Zhu, Y. Zhai, D. Wang, and S. Dong, "Onestep, solvothermal synthesis of graphene-CdS and graphene$\mathrm{ZnS}$ quantum dot nanocomposites and their interesting photovoltaic properties," Nano Research, pp. 1-6, 2010.

[49] H. Kim, A. A. Abdala, and C. W. MacOsko, "Graphene/polymer nanocomposites," Macromolecules, vol. 43, no. 16, pp. 65156530, 2010.

[50] C. Berger, Z. Song, X. Li et al., "Electronic confinement and coherence in patterned epitaxial graphene," Science, vol. 312, no. 5777, pp. 1191-1196, 2006.

[51] W. A. de Heer, C. Berger, X. Wu et al., "Epitaxial graphene," Solid State Communications, vol. 143, no. 1-2, pp. 92-100, 2007.

[52] E. Rollings, G.-H. Gweon, S. Y. Zhou et al., "Synthesis and characterization of atomically thin graphite films on a silicon carbide substrate," Journal of Physics and Chemistry of Solids, vol. 67, no. 9-10, pp. 2172-2177, 2006.

[53] Z. H. Ni, W. Chen, X. F. Fan et al., "Raman spectroscopy of epitaxial graphene on a SiC substrate," Physical Review B, vol. 77, no. 11, pp. 115416-115422, 2008.

[54] T. Seyller, A. Bostwick, K. V. Emtsev et al., "Epitaxial graphene: a new material," Physica Status Solidi B, vol. 245, no. 7, pp. 14361446, 2008.

[55] M. J. Allen, V. C. Tung, and R. B. Kaner, "Honeycomb carbon: a review of graphene," Chemical Reviews, vol. 110, no. 1, pp. 132$145,2010$.

[56] J. Hass, W. A. De Heer, and E. H. Conrad, "The growth and morphology of epitaxial multilayer graphene," Journal of Physics Condensed Matter, vol. 20, no. 32, Article ID 323202, 2008.

[57] J. Kedzierski, P. Hsu, P. Healey et al., "Epitaxial graphene transistors on $\mathrm{SiC}$ substrates," IEEE Transactions on Electron Devices, vol. 55, no. 8, pp. 2078-2085, 2008.

[58] C. Berger, Z. Song, X. Li et al., "Magnetotransport in high mobility epitaxial graphene," Physica Status Solidi A, vol. 204, no. 6, pp. 1746-1750, 2007.

[59] J. Wintterlin and M.-L. Bocquet, "Graphene on metal surfaces," Surface Science, vol. 603, no. 10-12, pp. 1841-1852, 2009.

[60] M. Sprinkle, P. Soukiassian, W. A. De Heer, C. Berger, and E. H. Conrad, "Epitaxial graphene: the material for graphene electronics," Physica Status Solidi, vol. 3, no. 6, pp. A91-A94, 2009.
[61] S. Li, D. Deng, Q. Shi, and S. Liu, "Electrochemical synthesis of a graphene sheet and gold nanoparticle-based nanocomposite, and its application to amperometric sensing of dopamine," Microchimica Acta, pp. 1-7, 2012.

[62] J. Yang, S. Deng, J. Lei, H. Ju, and S. Gunasekaran, "Electrochemical synthesis of reduced graphene sheet-AuPd alloy nanoparticle composites for enzymatic biosensing," Biosensors and Bioelectronics, vol. 29, no. 1, pp. 159-166, 2011.

[63] N. Liu, F. Luo, H. Wu, Y. Liu, C. Zhang, and J. Chen, "Onestep ionic-liquid-assisted electrochemical synthesis of ionicliquid-functionalized graphene sheets directly from graphite," Advanced Functional Materials, vol. 18, no. 10, pp. 1518-1525, 2008.

[64] Y. Zhu, S. Murali, W. Cai et al., "Graphene and graphene oxide: synthesis, properties, and applications," Advanced Materials, vol. 22 , no. 35, pp. 3906-3924, 2010.

[65] D. Galpaya, M. Wang, M. Liu, N. Motta, E. Waclawik, and C. Yan, "Recent advances in fabrication and characterization of graphene-polymer nanocomposites," Graphene, vol. 1, no. 2, pp. 30-49, 2012.

[66] C. N. R. Rao, A. K. Sood, R. Voggu, and K. S. Subrahmanyam, "Some novel attributes of graphene," Journal of Physical Chemistry Letters, vol. 1, no. 2, pp. 572-580, 2010.

[67] C. Soldano, A. Mahmood, and E. Dujardin, "Production, properties and potential of graphene," Carbon, vol. 48, no. 8, pp. 2127-2150, 2010.

[68] K. S. Novoselov, D. Jiang, F. Schedin et al., "Two-dimensional atomic crystals," Proceedings of the National Academy of Sciences of the United States of America, vol. 102, no. 30, pp. 10451-10453, 2005.

[69] T. A. Land, T. Michely, R. J. Behm, J. C. Hemminger, and G. Comsa, "STM investigation of single layer graphite structures produced on $\mathrm{Pt}(111)$ by hydrocarbon decomposition," Surface Science, vol. 264, no. 3, pp. 261-270, 1992.

[70] J. R. Potts, D. R. Dreyer, C. W. Bielawski, and R. S. Ruoff, "Graphene-based polymer nanocomposites," Polymer, vol. 52, no. 1, pp. 5-25, 2011.

[71] R. C. Daniel, D. A. Benjamin, G. Nageswara et al., "Experimental review of graphene," ISRN Condensed Matter Physics, vol. 2012, Article ID 501686, 56 pages, 2012.

[72] L. Chen, Y. Hernandez, X. Feng, and K. Müllen, "From nanographene and graphene nanoribbons to graphene sheets: chemical synthesis," Angewandte Chemie, vol. 51, no. 31, pp. 7640-7654, 2012.

[73] A. Mattausch and O. Pankratov, "Density functional study of graphene overlayers on SiC," Physica Status Solidi B, vol. 245, no. 7, pp. 1425-1435, 2008.

[74] Y. Fogel, L. Zhi, A. Rouhanipour, D. Andrienko, H. J. Räder, and K. Müllen, "Graphitic nanoribbons with dibenzo[e,l]pyrene repeat units: synthesis and self-assembly," Macromolecules, vol. 42, no. 18, pp. 6878-6884, 2009.

[75] L. Dössel, L. Gherghel, X. Feng, and K. Müllen, "Graphene nanoribbons by chemists: nanometer-sized, soluble, and defectfree," Angewandte Chemie, vol. 123, no. 11, pp. 2588-2591, 2011.

[76] C. Berger, Z. Song, T. Li et al., "Ultrathin epitaxial graphite: $2 \mathrm{D}$ electron gas properties and a route toward graphene-based nanoelectronics," Journal of Physical Chemistry B, vol. 108, no. 52, pp. 19912-19916, 2004.

[77] K. Singh, O. Anil, and S. K. Dhawan, "Polymer-graphene nanocomposites: preparation, characterization, properties, and 
applications," in Nanocomposites-New Trends and Developments, F. Ebrahimi, Ed., pp. 37-72, InTech, Hampshire, UK, 2012.

[78] L. Zhi and K. Müllen, "A bottom-up approach from molecular nanographenes to unconventional carbon materials," Journal of Materials Chemistry, vol. 18, no. 13, pp. 1472-1484, 2008.

[79] C. Kim, B. Min, and W. Jung, "Preparation of graphene sheets by the reduction of carbon monoxide," Carbon, vol. 47, no. 6, pp. 1610-1612, 2009.

[80] A. Hirsch, "Unzipping carbon nanotubes: a peeling method for the formation of graphene nanoribbons," Angewandte Chemie, vol. 48, no. 36, pp. 6594-6596, 2009.

[81] I. Janowska, O. Ersen, T. Jacob et al., "Catalytic unzipping of carbon nanotubes to few-layer graphene sheets under microwaves irradiation," Applied Catalysis A, vol. 371, no. 1-2, pp. 22-30, 2009.

[82] S. Mohammadi, Z. Kolahdouz, S. Darbari, S. Mohajerzadeh, and N. Masoumi, "Graphene formation by unzipping carbon nanotubes using a sequential plasma assisted processing," Carbon, vol. 52, pp. 451-463, 2013.

[83] W. Zhang, J. Cui, C. Tao et al., "A strategy for producing pure single-layer graphene sheets based on a confined self-assembly approach," Angewandte Chemie, vol. 48, no. 32, pp. 5864-5868, 2009.

[84] K. Sheng, Y. Xu, C. Li, and G. Shi, "High-performance selfassembled graphene hydrogels prepared by chemical reduction of graphene oxide," New Carbon Materials, vol. 26, no. 1, pp. 915, 2011.

[85] Q. Liu, A. Ishibashi, T. Fujigaya et al., "Formation of selforganized graphene honeycomb films on substrates," Carbon, vol. 49, no. 11, pp. 3424-3429, 2011.

[86] H. C. Schniepp, J. Li, M. J. McAllister et al., "Functionalized single graphene sheets derived from splitting graphite oxide," Journal of Physical Chemistry B, vol. 110, no. 17, pp. 8535-8539, 2006.

[87] G. Wang, X. Shen, B. Wang, J. Yao, and J. Park, "Synthesis and characterisation of hydrophilic and organophilic graphene nanosheets," Carbon, vol. 47, no. 5, pp. 1359-1364, 2009.

[88] J. R. Lomeda, C. D. Doyle, D. V. Kosynkin, W. Hwang, and J. M. Tour, "Diazonium functionalization of surfactant-wrapped chemically converted graphene sheets," Journal of the American Chemical Society, vol. 130, no. 48, pp. 16201-16206, 2008.

[89] M. J. McAllister, J. Li, D. H. Adamson et al., "Single sheet functionalized graphene by oxidation and thermal expansion of graphite," Chemistry of Materials, vol. 19, no. 18, pp. 4396-4404, 2007.

[90] M. M. Gudarzi, S. H. Aboutalebi, N. Yousefi et al., "Self-aligned graphene sheets-polyurethane nanocomposites," in 2011 MRS Spring Meeting, pp. 17-22, usa, April 2011.

[91] G. Zhao, T. Wen, C. Chen, and X. Wang, "Synthesis of graphenebased nanomaterials and their application in energy-related and environmental-related areas," RSC Advances, vol. 2, no. 25, pp. 9286-9303, 2012.

[92] B. Zhang, W. H. Lee, R. Piner et al., "Low-temperature chemical vapor deposition growth of graphene from toluene on electropolished copper foils," ACS Nano, vol. 6, no. 3, pp. 2471-2476, 2012.

[93] X. Li, C. W. Magnuson, A. Venugopal et al., "Large-area graphene single crystals grown by low-pressure chemical vapor deposition of methane on copper," Journal of the American Chemical Society, vol. 133, no. 9, pp. 2816-2819, 2011.
[94] X. Li, C. W. Magnuson, A. Venugopal et al., "Graphene films with large domain size by a two-step chemical vapor deposition process," Nano Letters, vol. 10, no. 11, pp. 4328-4334, 2010.

[95] K. V. Emtsev, A. Bostwick, K. Horn et al., "Towards wafersize graphene layers by atmospheric pressure graphitization of silicon carbide," Nature Materials, vol. 8, no. 3, pp. 203-207, 2009.

[96] H. Huang, W. Chen, S. Chen, and A. T. S. Wee, "Bottom-up growth of epitaxial graphene on $6 \mathrm{H}-\mathrm{SiC}(0001)$," ACS Nano, vol. 2, no. 12, pp. 2513-2518, 2008.

[97] Q. Zheng, W. H. Ip, X. Lin et al., “Transparent conductive films consisting of ultralarge graphene sheets produced by LangmuirBlodgett assembly," ACS Nano, vol. 5, no. 7, pp. 6039-6051, 2011.

[98] Q. B. Zheng, M. M. Gudarzi, S. J. Wang, Y. Geng, Z. Li, and J. Kim, "Improved electrical and optical characteristics of transparent graphene thin films produced by acid and doping treatments," Carbon, vol. 49, no. 9, pp. 2905-2916, 2011.

[99] L. J. Cote, F. Kim, and J. Huang, "Langmuir-blodgett assembly of graphite oxide single layers," Journal of the American Chemical Society, vol. 131, no. 3, pp. 1043-1049, 2009.

[100] P. H. Lv, G. Wang, Y. Wan, J. Liu, Q. Liu, and F. Ma, "Bibliometric trend analysis on global graphene research," Scientometrics, vol. 88, no. 2, pp. 399-419, 2011.

[101] P. Shapira, J. Youtie, and S. Arora, "Early patterns of commercial activity in graphene," Journal of Nanoparticle Research, vol. 14, no. 4, p. 811, 2012.

[102] A. K. Geim and K. S. Novoselov, “The rise of graphene," Nature Materials, vol. 6, no. 3, pp. 183-191, 2007.

[103] O. C. Compton and S. T. Nguyen, "Graphene oxide, highly reduced graphene oxide, and graphene: versatile building blocks for carbon-based materials," Small, vol. 6, no. 6, pp. 711$723,2010$.

[104] K. I. Winey and R. A. Vaia, "Polymer nanocomposites," MRS Bulletin, vol. 32, no. 4, pp. 314-319, 2007.

[105] T. Premkumar and K. E. Geckeler, "Graphene-DNA hybrid materials: assembly, applications, and prospects," Progress in Polymer Science, vol. 37, no. 4, pp. 515-529, 2012.

[106] T. Kuilla, S. Bhadra, D. Yao, N. H. Kim, S. Bose, and J. H. Lee, "Recent advances in graphene based polymer composites," Progress in Polymer Science, vol. 35, no. 11, pp. 1350-1375, 2010.

[107] T. Zhang, Q. Xue, S. Zhang, and M. Dong, "Theoretical approaches to graphene and graphene-based materials," Nano Today, vol. 7, no. 3, pp. 180-200, 2012.

[108] B. Z. Jang and A. Zhamu, "Processing of nanographene platelets (NGPs) and NGP nanocomposites: a review," Journal of Materials Science, vol. 43, no. 15, pp. 5092-5101, 2008.

[109] J. J. Mack, L. M. Viculis, A. Ali et al., "Graphite nanoplatelet reinforcement of electrospun polyacrylonitrile nanofibers," Advanced Materials, vol. 17, no. 1, pp. 77-80, 2005.

[110] P. K. Hansma, P. J. Turner, and R. S. Ruoff, “Optimized adhesives for strong, lightweight, damage-resistant, nanocomposite materials: new insights from natural materials," Nanotechnology, vol. 18, no. 4, Article ID 044026, 2007.

[111] T. Ramanathan, A. A. Abdala, S. Stankovich et al., "Functionalized graphene sheets for polymer nanocomposites," Nature Nanotechnology, vol. 3, no. 6, pp. 327-331, 2008.

[112] B. Das, K. Eswar Prasad, U. Ramamurty, and C. N. R. Rao, "Nano-indentation studies on polymer matrix composites reinforced by few-layer graphene," Nanotechnology, vol. 20, no. 12, Article ID 125705, 2009. 
[113] A. Yu, P. Ramesh, M. E. Itkis, E. Bekyarova, and R. C. Haddon, "Graphite nanoplatelet-epoxy composite thermal interface materials," Journal of Physical Chemistry C, vol. 111, no. 21, pp. 7565-7569, 2007.

[114] X. Zhang, Y. Huang, Y. Wang, Y. Ma, Z. Liu, and Y. Chen, "Synthesis and characterization of a graphene-C60 hybrid material," Carbon, vol. 47, no. 1, pp. 334-337, 2009.

[115] Z. Liu, Y. Xu, X. Zhang, X. Zhang, Y. Chen, and J. Tian, "Porphyrin and fullerene covalently functionalized graphene hybrid materials with large nonlinear optical properties," Journal of Physical Chemistry B, vol. 113, no. 29, pp. 9681-9686, 2009.

[116] T. J. Booth, P. Blake, R. R. Nair et al., "Macroscopic graphene membranes and their extraordinary stiffness," Nano Letters, vol. 8, no. 8, pp. 2442-2446, 2008.

[117] N. A. Luechinger, N. Booth, G. Heness, S. Bandyopadhyay, R. N. Grass, and W. J. Stark, "Surfactant-free, melt-processable metal-polymer hybrid materials: use of graphene as a dispersing agent," Advanced Materials, vol. 20, no. 16, pp. 3044-3049, 2008.

[118] S. Watcharotone, D. A. Diking Sasha Stankovich, R. Pinery et al., "Graphene-silica composite thin films as transparent conductors," Nano Letters, vol. 7, no. 7, pp. 1888-1892, 2007.

[119] H. Chen, M. B. Müller, K. J. Gilmore, G. G. Wallace, and D. Li, "Mechanically strong, electrically conductive, and biocompatible graphene paper," Advanced Materials, vol. 20, no. 18, pp. 3557-3561, 2008.

[120] J. Cheng, H. Xin, H. Zheng, and B. Wang, "One-pot synthesis of carbon coated-SnO2/graphene-sheet nanocomposite with highly reversible lithium storage capability," Journal of Power Sources, vol. 232, pp. 52-158, 2013.

[121] S. D. Perera, A. D. Liyanage, N. Nijem, J. P. Ferraris, Y. J. Chabal, and J. K. J. Balkus, "Vanadium oxide nanowire-Graphene binder free nanocomposite paper electrodes for supercapacitors: a facile green approach," Journal of Power Sources, vol. 230, pp. 130-137, 2013.

[122] J. H. Lee, J. Marroquin, K. Y. Rhee, S. J. Park, and D. Hui, "Cryomilling application of graphene to improve material properties of graphene/chitosan nanocomposites," Composites $B$, vol. 45 , no. 1, pp. 682-687, 2013.

[123] J. Guo, L. Ren, R. Wang, C. Zhang, Y. Yang, and T. Liu, "Water dispersible graphene noncovalently functionalized with tryptophan and its poly(vinyl alcohol) nanocomposite," Composites $B$, vol. 42, no. 8, pp. 2130-2135, 2011.

[124] M. O. Ansari, S. K. Yadav, J. W. Cho, and F. Mohammad, "Thermal stability in terms of DC electrical conductivity retention and the efficacy of mixing technique in the preparation of nanocomposites of graphene/polyaniline over the carbon nanotubes/polyaniline," Composites B, vol. 47, pp. 155-161, 2013.

[125] G. W. Jeon, J. An, and Y. G. Jeong, "High performance cellulose acetate propionate composites reinforced with exfoliated graphene," Composites B, vol. 43, no. 8, pp. 3412-3418, 2012.

[126] P. Avouris and C. Dimitrakopoulos, "Graphene: synthesis and applications," Materials Today, vol. 15, no. 3, pp. 86-97, 2012.

[127] X. Huang, Z. Yin, S. Wu et al., "Graphene-based materials: synthesis, characterization, properties, and applications," Small, vol. 7, no. 14, pp. 1876-1902, 2011.

[128] H. Shen, L. Zhang, M. Liu, and Z. Zhang, "Biomedical applications of Graphene," Theranostics, vol. 2, no. 3, pp. 283-294, 2012.

[129] W. Choi, I. Lahiri, R. Seelaboyina, and Y. S. Kang, "Synthesis of graphene and its applications: a review," Critical Reviews in Solid State and Materials Sciences, vol. 35, no. 1, pp. 52-71, 2010.
[130] W. Hu, C. Peng, W. Luo et al., "Graphene-based antibacterial paper," ACS Nano, vol. 4, no. 7, pp. 4317-4323, 2010.

[131] K. Liao, Y. Lin, C. W. MacOsko, and C. L. Haynes, "Cytotoxicity of graphene oxide and graphene in human erythrocytes and skin fibroblasts," ACS Applied Materials and Interfaces, vol. 3, no. 7, pp. 2607-2615, 2011.

[132] S. Liu, T. H. Zeng, M. Hofmann et al., "Antibacterial activity of graphite, graphite oxide, graphene oxide, and reduced graphene oxide: membrane and oxidative stress," ACS Nano, vol. 5, no. 9, pp. 6971-6980, 2011.

[133] C. M. Santos, M. C. R. Tria, R. A. M. V. Vergara, F. Ahmed, R. C. Advincula, and D. F. Rodrigues, "Antimicrobial graphene polymer (PVK-GO) nanocomposite films," Chemical Communications, vol. 47, no. 31, pp. 8892-8894, 2011.

[134] C. M. Santos, J. Mangadlao, F. Ahmed, A. Leon, R. C. Advincula, and D. F. Rodrigues, "Graphene nanocomposite for biomedical applications: fabrication, antimicrobial and cytotoxic investigations," Nanotechnology, vol. 23, no. 39, Article ID 395101, 2012.

[135] M. I. E. Carpio, C. M. Santos, X. Wei, and D. F. Rodrigues, “Toxicity of a polymer-graphene oxide composite against bacterial planktonic cells, biofilms, and mammalian cells," Nanoscale, vol. 4, no. 15, pp. 4746-4756, 2012.

[136] E. Peng, E. S. G. Choo, P. Chandrasekharan et al., "Synthesis of manganese ferrite/Graphene oxide nanocomposites for biomedical applications," Small, vol. 8, no. 23, pp. 3620-3630, 2012.

[137] Z. Wu, X. D. Chen, S. Zhu et al., "Enhanced sensitivity of ammonia sensor using graphene/polyaniline nanocomposite," Sensors and Actuators B, vol. 178, pp. 485-493, 2013.

[138] F. L. Meng, H. H. Li, L. T. Kong et al., "Parts per billion-level detection of benzene using $\mathrm{SnO} 2 /$ graphene nanocomposite composed of sub- $6 \mathrm{~nm} \mathrm{SnO}$ nanoparticles," Analytica Chimica Acta, vol. 736, pp. 100-107, 2012.

[139] P. K. Sahoo, B. Panigrahy, S. Sahoo, A. K. Satpati, D. Li, and D. Bahadur, "In situ synthesis and properties of reduced graphene oxide/Bi nanocomposites: as an electroactive material for analysis of heavy metals," Biosensors and Bioelectronics, vol. 43, pp. 293-296, 2013.

[140] D. Zhang, Y. Zhang, L. Zheng, Y. Z. Zhan, and L. C. He, "Graphene oxide/poly-L-lysine assembled layer for adhesion and electrochemical impedance detection of leukemia K562 cancer cells," Biosensors and Bioelectronics, vol. 42, pp. 112-118, 2013.

[141] J. Li, D. Kuang, Y. Feng et al., "Green synthesis of silver nanoparticles-graphene oxide nanocomposite and its application in electrochemical sensing of tryptophan," Biosensors and Bioelectronics, vol. 42, pp. 198-206, 2013.

[142] H. Xia, D. D. Zhu, Y. Fu, and X. Wang, "CoFe $\mathrm{O}_{4}$-graphene nanocomposite as a high-capacity anode material for lithiumion batteries," Electrochimica Acta, vol. 83, pp. 166-174, 2012.

[143] Y. Zhao, Y. Huang, Q. Wang, X. Wang, and M. Zong, "Carbondoped $\mathrm{Li}_{2} \mathrm{SnO}_{3}$ /graphene as an anode material for lithium-ion batteries," Ceramics International, vol. 39, no. 2, pp. 1741-1747, 2013.

[144] H. Xia, Y. Qian, Y. Fu, and X. Wang, "Graphene anchored with $\mathrm{ZnFe}_{2} \mathrm{O}_{4}$ nanoparticles as a high-capacity anode material for lithium-ion batteries," Solid State Sciences, vol. 17, pp. 67-71, 2013.

[145] L. Zhang, S. Wang, D. Cai et al., "Li3V2(PO4)3@C/graphene composite with improved cycling performance as cathode material for lithium-ion batteries," Electrochimica Acta, vol. 91, pp. 108-113, 2013. 
[146] H. Yang, T. Song, S. Lee et al., "Tin indium oxide/graphene nanosheet nanocomposite as an anode material for lithium ion batteries with enhanced lithium storage capacity and rate capability," Electrochimica Acta, vol. 91, pp. 275-281, 2013.

[147] J. Zhu, D. Wang, L. Wang, X. Lang, and W. You, "Facile synthesis of sulfur coated $\mathrm{SnO}_{2}$-graphene nanocomposites for enhanced lithium ion storage," Electrochimica Acta, vol. 91, pp. 323-329, 2013.

[148] S. Liu, J. Wang, J. Zeng et al., ““'Green” electrochemical synthesis of Pt/graphene sheet nanocomposite film and its electrocatalytic property," Journal of Power Sources, vol. 195, no. 15, pp. 4628-4633, 2010.

[149] X. Fu, J. Jin, Y. Liu et al., "Graphene- xerogel- based nonprecious metal catalyst for oxygen reduction reaction," Electrochemistry Communications, vol. 28, pp. 5-8, 2013.

[150] L. Wang, Y. Zhang, and Z. Li, "Chemical reduced graphene oxide/AuPtPd nanocomposite for enhanced electrocatalytic ability," Materials Letters, vol. 94, pp. 179-182, 2013.

[151] S. Yu, Q. Liu, W. Yang, K. Han, Z. Wang, and H. Zhu, "Graphene$\mathrm{CeO}_{2}$ hybrid support for Pt nanoparticles as potential electrocatalyst for direct methanol fuel cells," Electrochimica Acta, vol. 94, pp. 245-251, 2013.

[152] Y. Cao, C. Xu, X. Wu, X. Wang, L. Xing, and K. Scott, "A poly (ethylene oxide)/graphene oxide electrolyte membrane for low temperature polymer fuel cells," Journal of Power Sources, vol. 196, no. 20, pp. 8377-8382, 2011.

[153] G. Wang, S. Zhuo, and W. Xing, "Graphene/polyaniline nanocomposite as counter electrode of dye-sensitized solar cells," Materials Letters, vol. 69, pp. 27-29, 2012.

[154] C. Y. Liu, K. C. Huang, P. H. Chung et al., "Graphene-modified polyaniline as the catalyst material for the counter electrode of a dye-sensitized solar cell," Journal of Power Sources, vol. 217, pp. 152-157, 2012.

[155] J. J. Zeng, C. L. Tsai, and Y. J. Lin, "Hybrid photovoltaic devices based on the reduced graphene oxide-based polymer composite and n-type GaAs," Synthetic Metals, vol. 162, no. 15-16, pp. 14111415, 2012.

[156] C. Y. Neo and J. Ouyang, "The production of organogels using graphene oxide as the gelator for use in high-performance quasi-solid state dye-sensitized solar cells," Carbon, vol. 54, pp. 48-57, 2013.

[157] R. Bajpai, S. Roy, N. Koratkar, and D. S. Misra, "NiO nanoparticles deposited on graphene platelets as a cost-effective counter electrode in a dye sensitized solar cell," Carbon, vol. 56, pp. 5663, 2013.

[158] W. Y. Cheng, C. C. Wang, and S. Y. Lu, "Graphene aerogels as a highly efficient counter electrode material for dye-sensitized solar cells," Carbon, vol. 54, pp. 291-299, 2013.

[159] S. Goswami, U. N. Maiti, S. Maiti, S. Nandy, M. K. Mitra, and K. K. Chattopadhyay, "Preparation of graphene-polyaniline composites by simple chemical procedure and its improved field emission properties," Carbon, vol. 49, no. 7, pp. 2245-2252, 2011.

[160] Z. J. Li, B. C. Yang, G. Q. Yun, S. R. Zhang, M. Zhang, and M. X. Zhao, "Synthesis of Sn nanoparticle decorated graphene sheets for enhanced field emission properties," Journal of Alloys and Compounds, vol. 550, pp. 353-357, 2013.

[161] F. Alvi, M. K. Ram, P. A. Basnayaka, E. Stefanakos, Y. Goswami, and A. Kumar, "Graphene-polyethylenedioxythiophene conducting polymer nanocomposite based supercapacitor," Electrochimica Acta, vol. 56, no. 25, pp. 9406-9412, 2011.
[162] H. Gómez, M. K. Ram, F. Alvi, P. Villalba, E. Stefanakos, and A. Kumar, "Graphene-conducting polymer nanocomposite as novel electrode for supercapacitors," Journal of Power Sources, vol. 196, no. 8, pp. 4102-4108, 2011.

[163] Y. Zhan, X. Yang, H. Guo, J. Yang, F. Meng, and X. Liu, "Crosslinkable nitrile functionalized graphene oxide/poly(arylene ether nitrile) nanocomposite films with high mechanical strength and thermal stability," Journal of Materials Chemistry, vol. 22, no. 12, pp. 5602-5608, 2012.

[164] S. Sahoo, S. Dhibar, G. Hatui, P. Bhattacharya, and C. K. Das, "Graphene/polypyrrole nanofiber nanocomposite as electrode material for electrochemical supercapacitor," Polymer, vol. 54, no. 3, pp. 1033-1042, 2013.

[165] Q. Liu, O. Nayfeh, M. H. Nayfeh, and T. Yau S, "Flexible supercapacitor sheets based on hybrid nanocomposite materials," Nano Energy, vol. 2, no. 1, pp. 133-137, 2013.

[166] A. Pendashteh, M. F. Mousavi, and M. S. Rahmanifar, "Fabrication of anchored copper oxide nanoparticles on graphene oxide nanosheets via an electrostatic coprecipitation and its application as supercapacitor," Electrochimica Acta, vol. 88, pp. 347-357, 2013.

[167] H. Heli, H. Yadegari, and A. Jabbari, "Graphene nanosheetspoly(o-aminophenol) nanocomposite for supercapacitor applications," Materials Chemistry and Physics, vol. 134, no. 1, pp. 2125, 2012.

[168] P. A. Basnayaka, M. K. Ram, E. Stefanakos, and A. Kumar, "Supercapacitors based on graphene-polyaniline derivative nanocomposite electrode materials," Electrochimica Acta, vol. 92, pp. 376-382, 2013.

[169] B. Yuan, C. Xu, D. Deng et al., "Graphene oxide/nickel oxide modified glassy carbon electrode for supercapacitor and nonenzymatic glucose sensor," Electrochimica Acta, vol. 88, pp. 708712, 2013

[170] Y. Li, H. Peng, G. Li, and K. Chen, "Synthesis and electrochemical performance of sandwich-like polyaniline/graphene composite nanosheets," European Polymer Journal, vol. 48, no. 8, pp. 1406-1412, 2012.

[171] R. B. Rakhi and H. N. Alshareef, "Enhancement of the energy storage properties of supercapacitors using graphene nanosheets dispersed with metal oxide-loaded carbon nanotubes," Journal of Power Sources, vol. 196, no. 20, pp. 8858-8865, 2011.

[172] G. Ma, H. Peng, J. Mu, H. Huang, X. Zhou, and Z. Lei, “In situ intercalative polymerization of pyrrole in graphene analogue of MoS2 as advanced electrode material in supercapacitor," Journal of Power Sources, vol. 229, no. 1, pp. 72-78, 2013.

[173] W. L. Song, L. M. Veca, C. Y. Kong et al., "Polymeric nanocomposites with graphene sheets-Materials and device for superior thermal transport properties," Polymer, vol. 53, no. 18, pp. 39103916, 2012.

[174] G. Gedler, M. Antunes, V. Realinho, and J. I. Velasco, "Thermal stability of polycarbonate-graphene nanocomposite foams," Polymer Degradation and Stability, vol. 97, no. 8, pp. 1297-1304, 2012.

[175] S. K. Yadav and J. W. Cho, "Functionalized graphene nanoplatelets for enhanced mechanical and thermal properties of polyurethane nanocomposites," Applied Surface Science, vol. 266, no. 1, pp. 360-367, 2013.

[176] H. Huang, P. Ren, J. Chen, W. Zhang, X. Ji, and Z. Li, "High barrier graphene oxide nanosheet/poly(vinyl alcohol) nanocomposite films," Journal of Membrane Science, vol. 409410, pp. 156-163, 2012. 
[177] H. Wu and L. T. Drzal, "Graphene nanoplatelet paper as a light-weight composite with excellent electrical and thermal conductivity and good gas barrier properties," Carbon, vol. 50, no. 3, pp. 1135-1145, 2012.

[178] S. K. Kumar, M. Castro, A. Saiter et al., "Development of poly (isobutylene-co-isoprene) / reduced graphene oxide nanocomposites for barrier, dielectric and sensing applications," Materials Letters, vol. 96, no. 1, pp. 109-112, 2013.

[179] C. H. Chang, T. C. Huang, C. W. Peng et al., "Novel anticorrosion coatings prepared from polyaniline/graphene composites," Carbon, vol. 50, no. 14, pp. 5044-5051, 2012.

[180] G. Y. Kim, M. Choi, D. Lee, and C. Ha, “2D-Aligned graphene sheets in transparent polyimide/graphene nanocomposite films based on noncovalent interactions between poly(amic acid) and graphene carboxylic acid," Macromolecular Materials and Engineering, vol. 297, no. 4, pp. 303-311, 2012.

[181] A. F. Ávila, M. I. Yoshida, M. G. R. Carvalho, E. C. Dias, and J. Á. Junior, "An investigation on post-fire behavior of hybrid nanocomposites under bending loads," Composites $B$, vol. 41, no. 5, pp. 380-387, 2010.

[182] Y. Fan, M. Estili, G. Igarashi, W. Jiang, and A. Kawasaki, "The effect of homogeneously dispersed few-layer graphene on microstructure and mechanical properties of $\mathrm{Al} 2 \mathrm{O} 3$ nanocomposites," Journal of the European Ceramic Society, vol. 34, no. 2, pp. 443-451, 2013.

[183] P. Miranzo, C. Ramírez, B. R. Manso et al., "In situ processing of electrically conducting graphene/SiC nanocomposites," Journal of the European Ceramic Society, vol. 33, no. 10, pp. 1665-1674, 2013.

[184] P. Hvizdoš, J. Dusza, and C. Balázsi, "Tribological properties of Si3N4-graphene nanocomposites," Journal of the European Ceramic Society, vol. 33, no. 12, pp. 2359-2364, 2013.

[185] P. Kun, O. Tapasztó, F. Wéber, and C. Balázsi, "Determination of structural and mechanical properties of multilayer graphene added silicon nitride-based composites," Ceramics International, vol. 38, no. 1, pp. 211-216, 2012.

[186] F. Inam, B. R. Bhat, T. Vo, and W. M. Daoush, "Structural health monitoring capabilities in ceramic-carbon nanocomposites," Ceramics International, 2013.

[187] G. B. Yadhukulakrishnan, S. Karumuri, A. Rahman, R. P. Singh, A. K. Kalkan, and S. P. Harimkar, "Spark plasma sintering of graphene reinforced zirconium diboride ultra-high temperature ceramic composites," Ceramics International, vol. 39, no. 6, pp. 6637-6646, 2013.

[188] J. Liu, H. Yan, M. J. Reece, and K. Jiang, “Toughening of zirconia/alumina composites by the addition of graphene platelets," Journal of the European Ceramic Society, vol. 32, no. 16, pp. 41854193, 2012.

[189] H. Liem and H. S. Choy, "Superior thermal conductivity of polymer nanocomposites by using graphene and boron nitride as fillers," Solid State Communications, vol. 163, pp. 41-45, 2013.

[190] D. Lahiri, E. Khaleghi, S. R. Bakshi, W. Li, E. A. Olevsky, and A. Agarwal, "Graphene-induced strengthening in spark plasma sintered tantalum carbide-nanotube composite," Scripta Materialia, vol. 68, no. 5, pp. 285-288, 2013.

[191] D. A. Pejaković, J. Marschall, M. R. George, B. R. Rogers, W. R. Nieveen, and V. Pajcini, "Synthesis of carbon-rich hafnia thin films by pulsed laser deposition," Journal of the European Ceramic Society, vol. 30, no. 11, pp. 2289-2300, 2010.

[192] K. I. Kim and T. W. Hong, "Hydrogen permeation of TiNgraphene membrane by hot press sintering (HPS) process," Solid State Ionics, vol. 225, pp. 699-702, 2012.
[193] N. R. Lee, S. S. Lee, K. I. Kim et al., "Fabrications and evaluations of hydrogen permeation on $\mathrm{Al}_{2} \mathrm{O}_{3} / \mathrm{CeO}_{2}$ /graphene (ACG) composites membrane by Hot Press Sintering (HPS)," International Journal of Hydrogen Energy, vol. 38, no. 18, pp. 7654-7658, 2013.

[194] D. R. Dreyer, S. Park, C. W. Bielawski, and R. S. Ruoff, "The chemistry of graphene oxide," Chemical Society Reviews, vol. 39, no. 1, pp. 228-240, 2010.

[195] F. Hussain, M. Hojjati, M. Okamoto, and R. E. Gorga, "Review article: polymer-matrix nanocomposites, processing, manufacturing, and application: an overview," Journal of Composite Materials, vol. 40, no. 17, pp. 1511-1575, 2006.

[196] D. C. Marcano, D. V. Kosynkin, J. M. Berlin et al., "Improved synthesis of graphene oxide," ACS Nano, vol. 4, no. 8, pp. 48064814, 2010.

[197] M. Yadav, K. Y. Rhee, I. H. Jung, and S. J. Park, "Ecofriendly synthesis, characterization and properties of a sodium carboxymethyl cellulose/graphene oxide nanocomposite film," Cellulose, vol. 20, no. 2, pp. 687-698, 2013.

[198] M. Segal, "Selling graphene by the ton," Nature Nanotechnology, vol. 4, no. 10, pp. 612-614, 2009. 

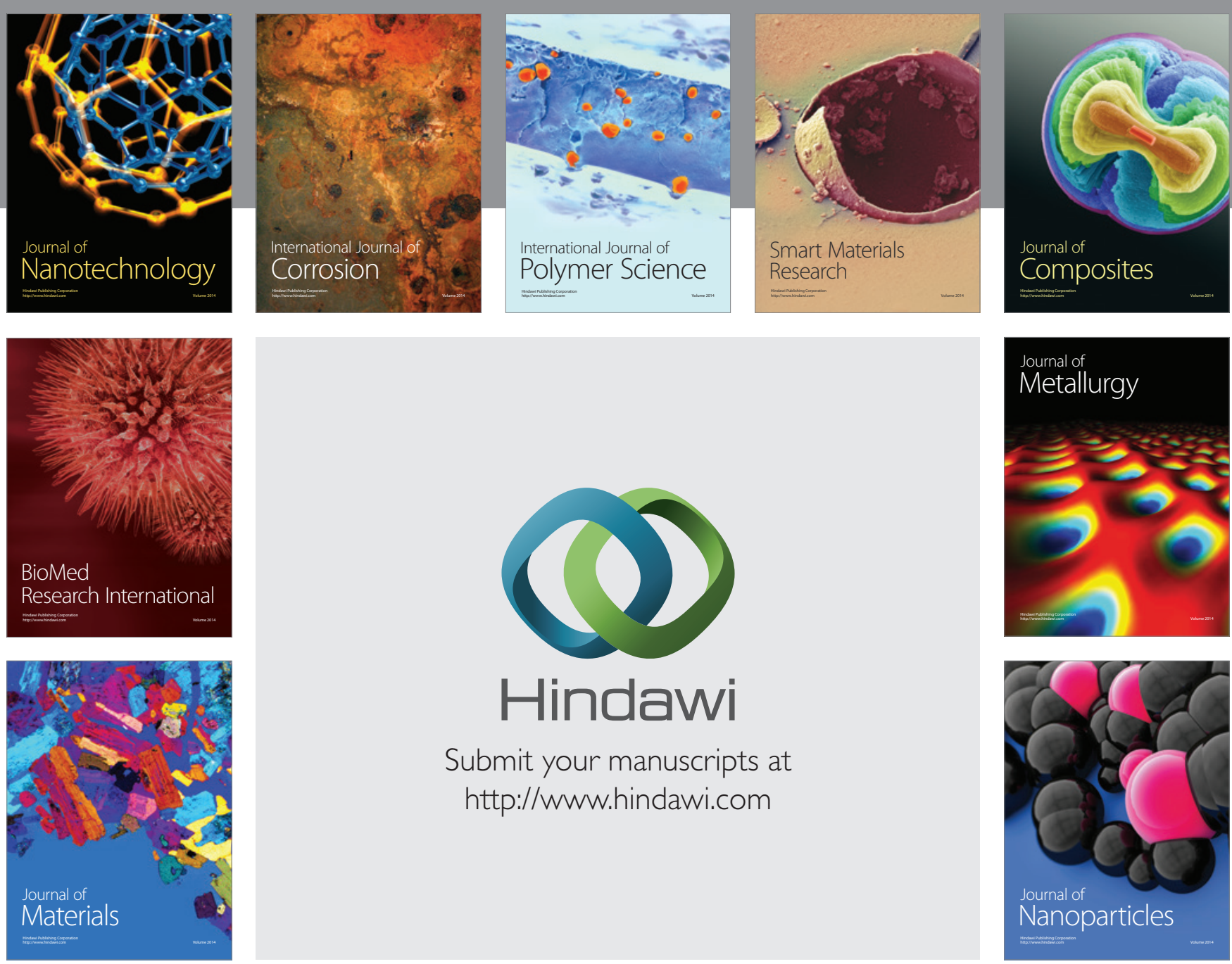

Submit your manuscripts at http://www.hindawi.com
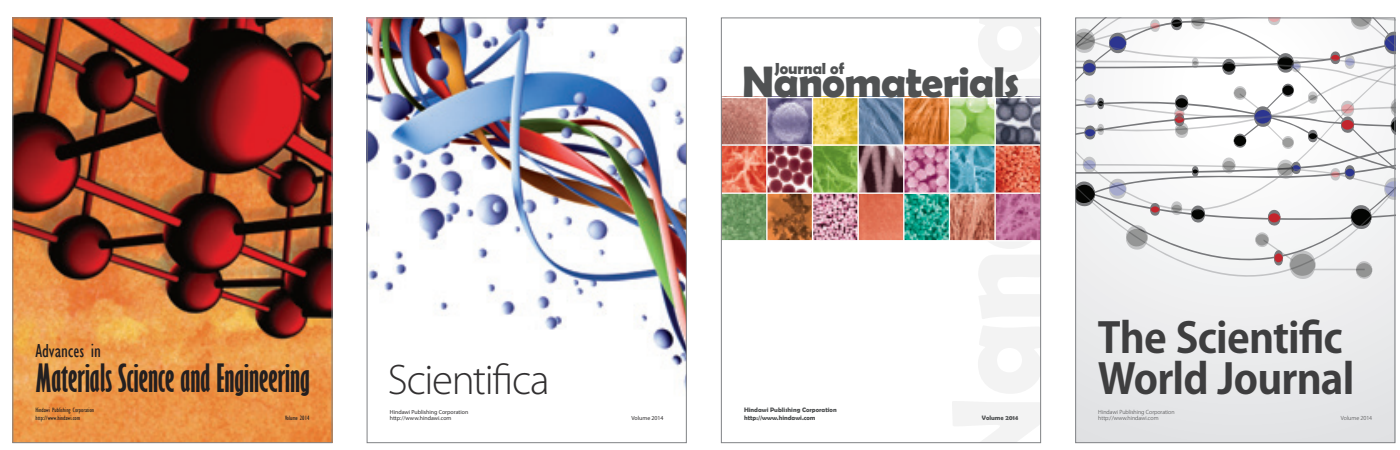

\section{The Scientific World Journal}
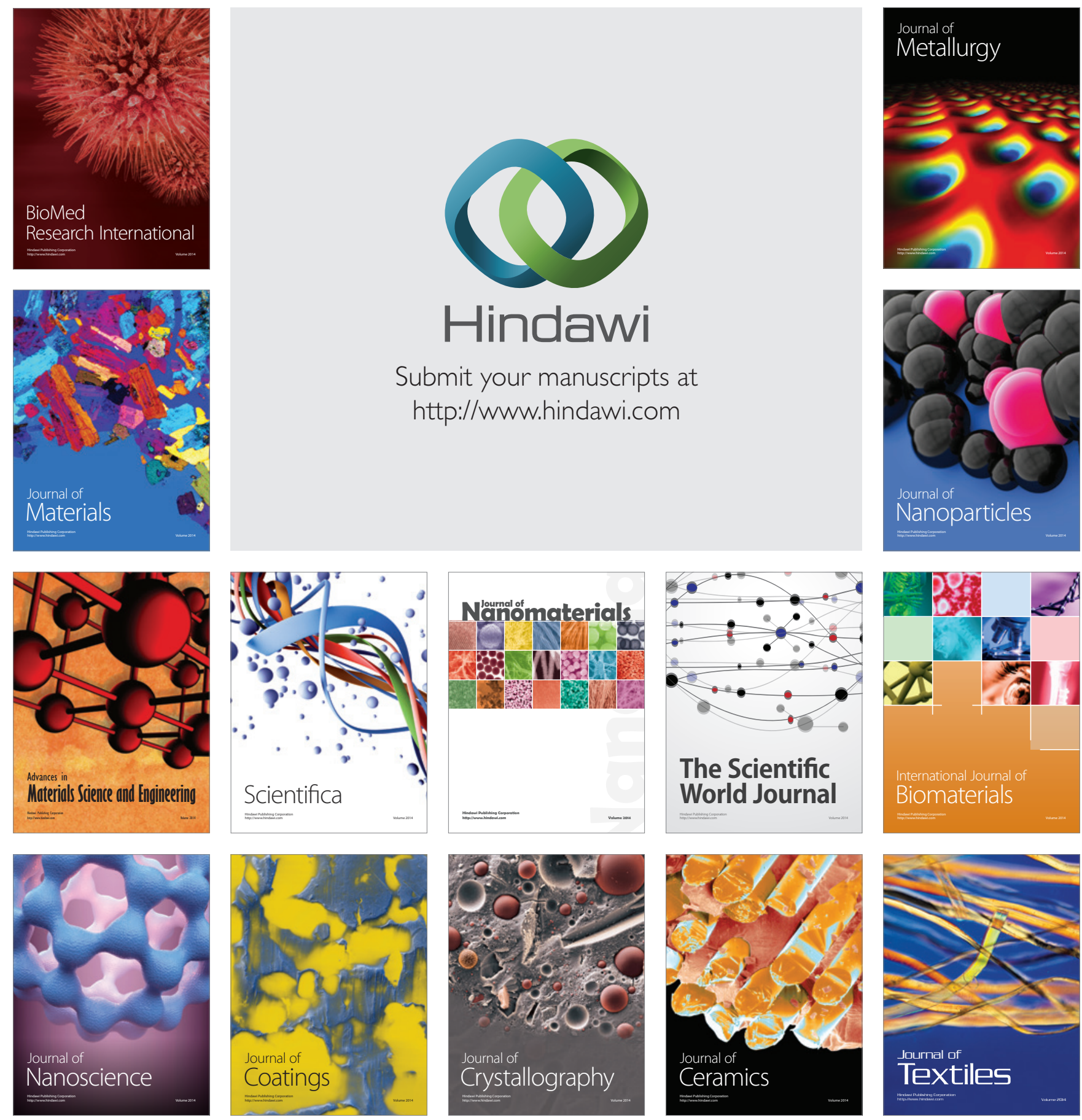